\title{
Behaviour of continuous reinforced concrete floor slabs subjected to different compartment fires
}

\author{
Yong Wang a,b, Yakun Duan ${ }^{\mathrm{a}}$, Shuai Ma ${ }^{\mathrm{a}}$, Zhaohui Huang ${ }^{*}$, , Yajun Zhang ${ }^{\mathrm{d}}$, Jiachao Wu ${ }^{\mathrm{a}}$, \\ Guanglin Yuan ${ }^{\text {a }}$, Meng Zhou ${ }^{\text {a }}$, Gengyuan Zhang ${ }^{\text {e }}$ \\ a Jiangsu Key Laboratory of Environmental Impact and Structural Safety in Engineering, China University \\ of Mining and Technology, Xuzhou, Jiangsu, 221116, China; \\ ${ }^{\mathrm{b}}$ State Key Laboratory for Geomechanics and Deep Underground Engineering, China University of Mining \\ and Technology, Xuzhou, Jiangsu 221116, China; \\ ${ }^{c}$ Department of Civil and Environmental Engineering, Brunel University London, Uxbridge, UK; \\ ${ }^{\mathrm{d}}$ College of Civil Engineering and Architecture, Zhejiang University, Hangzhou 310058, China; \\ ${ }^{e}$ China Academy of Building Research, Beijing, 100013, China;
}

\begin{abstract}
This paper presents the experimental results of four continuous reinforced concrete slabs with three compartments under different compartment fire scenarios. The research focuses on the quantitative relationships of the compartment fire temperatures, the temperature distribution along the thickness of the slabs, the vertical and horizontal deflections, the crack patterns and failure modes of the slabs and the corners' reaction forces. The results indicate that for a continuous floor slab, the central vertical deflection of the slab in the middle compartment is considerably affected by the vertical deflections of the slab in the two edge compartments. The boundary condition, the ratio and arrangement of the top reinforcement of the continuous slab, and the fire spreading scenarios have important effects on the failure mode of the slab in different compartments. It is evident that more severe cracking happened within the slab in the middle compartment compared to the two edge compartments. For the edge compartment, the slab may fail by large deflection and the integrity failure of the slab in the middle compartment may occur. Increasing reinforcement ratio and using the continuous reinforcement are the effective methods to prevent or delay the failure of the continuous slabs with any fire spreading scenarios.
\end{abstract}

Keywords: continuous concrete slab; fire test; compartment fire; temperature; deflection; crack; failure criterion.

* Corresponding author, E-mail address: zhaohui.huang@brunel.ac.uk (Z. Huang) 


\section{Introduction}

In recent years, the structural performance of reinforced concrete slabs in fire is a topic that has received significant research attentions. A review of the literatures indicates that there have been a lot of experimental and numerical studies on the fire performance of simply supported slabs under uniform fire [1-5]. For instance, Lim et al. [2-3] carried out the fire tests and numerical analysis on the three simply supported reinforced concrete slabs. Bailey and Toh [4-5] presented test results of forty-eight two-way simply supported small-scale reinforced concrete slabs at both ambient and elevated temperatures. Their results indicate that two-way slabs have good fire resistant performance due to tensile membrane action. However, due to the unrealistic temperature distributions (small-scale slabs) and neglecting the restraints between members [6], the fire tests on full-scale slabs are crucial to more accurately understand the structural behavior of two-way concrete slabs.

Thus, Wang and Dong [7] conducted fire tests on the two rectangular reinforced concrete slabs with simply supported and four-edge fixed conditions. For the simply supported slab, several cracks occurred parallel to the short span of the slab. For the four-edge fixed slab, plastic hinge lines of elliptic shape appeared on the top surface of the slab. Dong and Zhu [8] reported the fire test results of a rectangular concrete slab with two edges clamped and two edges simply supported. The two simply supported edges of the slabs were supported by steel balls and rollers on the furnace walls, and the other two clamped edges of the slab were supported by long knife supports along each support axis. Clearly, the tested slabs presented in Refs. [7-8] with no horizontal restraint were free to move horizontally, and thus the arch action or compressive membrane action cannot be reasonably considered during the fire tests. In recent years, Wang et al. [9, 10] conducted a series of full-scale fire tests on the reinforced concrete slabs which included five square slabs and four rectangular slabs under combined uniaxial in-plane and out-of-plane loading, along with vertical restraints at the four corners of the slabs. The test results indicate that the fire behaviour of the restrained slabs is dependent on the restraint type, restraint level and slab aspect ratio. In addition, the failure mode of the in-plane restrained slabs is considerably different compared to simply supported slabs.

Although the restraint effects on the fire response of the isolated concrete slabs were studied, the real structural continuity or interactions between members should be further investigated using continuous slabs subjected to fire. For instance, Chen [11] conducted six fire tests on the one-way three-span continuous RC slabs where different spans (one edge span, one middle span and edge-middle span) were subjected to fire. For one heated span, the position and number of its failure hinge was dependent on the length of hogging moment reinforcement and its position. In 
addition, Yang et al. [12] conducted two full-scale fire tests on the two-way concrete slabs supported by composite beams in a three-story steel-framed building. In those tests, a corner panel and an interior panel on the top floor of the building were heated by two specially designed furnaces, respectively. After that, Wang et al. [13] constructed a special furnace on the second floor of the same building to heat four panels (two by two) and steel beams on the third floor of the building. In 2015, to further understand the fire behavior of reinforced concrete floor slabs, a fire test was performed on six continuous panels (two by three) in this building [14]. The results indicate that deformations of the heated panels have an important relationship with the locations of the heat panels within the floor. Due to the structural continuity and the tensile membrane action, heated panels had good fire performances even under long duration fire. In all, the findings of the above research are similar to the Cardington fire tests [15]. The concrete floor slabs in the steel framed building perform better than the isolated individual member under fire conditions.

A review of the literature shows that the research on the fire behaviour of the concrete slabs was conducted by many researchers. However, several important problems exist: (1) the current fire resistant methods of the concrete slabs were mainly based on the uniform fire tests. In fact, for many real fire events, fires were observed to travel from one compartment to another compartment within the same floor or different floors [16-17]; (2) fewer travelling fire tests on the continuous slabs were conducted due to the limitation of test conditions. (3) compared to the uniform fire, travelling fire may result in different thermal and structural response of the slab, and thus the effectiveness of the conventional fire-resistant design method should be further investigated. As discussed in Refs. [18-20], the consideration of more realistic fire exposures, such as travelling fire, become important for assessing the fire behavior of concrete slabs. Therefore, the main objectives of this research are:

(1) to conduct a series of experiments on the continuous RC slabs subjected to different compartment fires and investigate their thermal and structural responses;

(2) to investigate the effects of the fire spreading direction, delay time, total fire duration, reinforcement ratio and reinforcement layout on the fire response of the continuous slabs;

(3) to understand different influencing factors on the failure behavior of the continuous slabs subjected to different compartment fires.

This paper presents, for the first time, four fire tests on the three-span continuous reinforced concrete floor slabs under different compartment fires. The research focuses on the quantitative relationships of the compartment fire temperatures, the temperature distribution along the thickness of the slabs, the vertical and horizontal deformations, the crack patterns and failure modes of the 
slabs and the corners' reaction forces. The research generates valuable test data which can be used by fellow researchers and structural engineers in the field of structural fire engineering.

\section{Test programme}

The experimental program consisted of conducting fire tests on the four three-span continuous slabs (named Slabs B1 to B4). The test variables mainly included reinforcement ratio or spacing, reinforcement layout and the different compartment fires. The heating fire curve of each fire compartment followed ISO834 fire for about $180 \mathrm{~min}$ then the fuel was stopped and the fire was dying down (cooling). There are three fire compartments and four combinations of three compartment fire curves.

\subsection{Test furnace}

A furnace was specially designed and constructed to have three fire compartments, as shown in Figs. 1(a)-1(c). The external furnace side wall was constructed from the external steel frame and internal mineral wool (thickness: $200 \mathrm{~mm}$ ). In addition, two internal walls in the furnace were composed of the refractory bricks (thickness: $200 \mathrm{~mm}$ ). The external dimension of the furnace was $4700 \mathrm{~mm} \times 1900 \mathrm{~mm} \times 2570 \mathrm{~mm}$, and one smoke vent $(200 \mathrm{~mm} \times 200 \mathrm{~mm})$ was placed in each fire compartment. Six oil burners in the south furnace wall provided thermal energy, and nine Type K thermocouples ( $2 \mathrm{~mm}$ diameter, named F-1, F-2 and F-3) were placed in the north furnace wall to measure the furnace temperature. The concrete slab was placed on top of the furnace and spanned over three fire compartments and heated from the bottom. The voids between the slab and the furnace were filled with mineral wool. Four types of fire sceneries were applied on the four slabs.

\subsection{Test specimens}

This research focuses mainly on the fire behaviour of the floor slabs for the residential multi-story reinforced concrete buildings in China [21-22]. Hence, the tested slabs mainly represent the thicker slabs (span-thickness ratio $\leq 20$ ), such as the concrete slabs used in the apartments in the residential high-rise buildings. According to the specifications of Chinese Standard GB50010-2010 [21] and the limitation of furnace dimension, four three-span continuous slabs with the dimensions of $4700 \mathrm{~mm} \times 2160 \mathrm{~mm} \times 100 \mathrm{~mm}$ were designed. In this case, the actual span-thickness ratio of the each span of the tested slab is about 15 . However, this is what can be done based on the current fire test facilities which are available at China University of Mining and Technology.

All slabs were cast using commercial concrete with the characteristic cube strength of $30 \mathrm{MPa}$ at 28 
day. The mix proportions in each cubic meter of concrete comprised of: cement $\left(\mathrm{kg} / \mathrm{m}^{3}\right): 360$; coarse carbonate aggregate $\left(\mathrm{kg} / \mathrm{m}^{3}\right): 1080$; fine aggregate $\left(\mathrm{kg} / \mathrm{m}^{3}\right): 790$; water $\left(\mathrm{kg} / \mathrm{m}^{3}\right): 170$. All slabs were cast on the same day (same batch) and were stored indoors in the laboratory to cure. The age of the concrete at the time of testing was: Slab B1 $=749$ days; Slab B2 $=701$ days; Slab B3 = 716 days and Slab B4 = 730 days.

For each slab, hot-rolled reinforcing bars of $8 \mathrm{~mm}$ diameter were used and the clear concrete cover was $15 \mathrm{~mm}$. The average yield strength and ultimate strength of the reinforcing steel were $414 \mathrm{MPa}$ and $475 \mathrm{MPa}$, respectively. The arrangement of the reinforcement in each slab was shown in Figs. 2(a)-2(c).

\subsection{Instrumentation}

According to the Chinese code for the design of building structures (GB50009-2001) [23], the value of the uniform distribution load was $2.0 \mathrm{kN} / \mathrm{m}^{2}$. The loads were applied using iron brick as shown in Fig. 3(a). The uniform load remained constant during each fire test. According to the Standard of concrete testing method of China [24], each slab was continuous over the interior support (refractory pellet) and was simply-supported on steel rollers at the exterior supports, as shown in Figs. 3(b) and 3(c). In addition, each corner was held down by a steel beam, and the restraint forces at the four corners of the slab were measured by the pressure transducers (Points P-1 to P-4), as shown in Fig. 3(d). Note that, each pressure transducer was placed at the top of the slab's corner.

Six thermocouple trees (such as Trees TA1 to TA6) were used to measure the temperatures of the slab within each fire compartment, as shown in Fig. 4(a). Each thermocouple tree consisted of 6 Type-K (0.5 mm diameter) thermocouples distributed vertically to measure the concrete temperature, and the distance between these points (Points T-1 to T-6) were $20 \mathrm{~mm}$. Meanwhile, four thermocouples were placed at the mid-depth of the bottom (Points R-1 and R-2) and top (Points R-3 and R-4) steel bars, as shown in Fig. 4(b).

Fig. 4(c) shows the position of the vertical and horizontal displacement transducers (with the travel limits ranging between $10 \mathrm{~mm}$ to $500 \mathrm{~mm}$ ). Three linear variable differential transformer LVDT's (Points VA, VB and VC) were placed to measure the central vertical deflection of the slab within 
each fire compartment, while its horizontal deformations were measured by four LVDT's (Points $\mathrm{H} 1, \mathrm{H} 2, \mathrm{H} 3$ and $\mathrm{H} 4)$.

\subsection{Test procedure}

Fire spreading in a building is a complex issue. However, normally, a fire spreads both horizontally and vertically within a building. For the horizontal case, fires spread progressively from one compartment to adjacent compartments due to the breakdown of compartment walls or non-closure of fire doors. For the vertical case, fires spread vertically due to broken windows. As discussed in Ref. [25], horizontally traveling fire would give a more realistic representation of the fire spreading within the same floor of the buildings.

According to Chinese design code [26] the fire resistance of a building is classified as Classes 1 to 4. For the civil buildings their fire resistances for Classes 1 to 4 are the same, i.e., $180 \mathrm{~min}$. However, to avoid the rapid fire spreading within a building the compartmentation is required. The fire resistance time of the fire compartment wall is based on the fire resistance class of the building. For the fire compartment walls, the required fire resistance times for Classes 1 to 4 buildings are 15 $\min , 30 \mathrm{~min}, 45 \mathrm{~min}$ and $60 \mathrm{~min}$, respectively [26]. Note that, for the residential building, the fire resistance of the fire compartment wall is at least $30 \mathrm{~min}$ [26].

Hence, in this research, for the ISO834 standard fire two time delays (30 min and $60 \mathrm{~min}$ ) were adopted to represent the fire spreading from one span to another span. Similar to Refs. [27-28], once the heating duration in the first span reached the defined time delay (30 min or $60 \mathrm{~min}$ ), then the fire was started in the adjacent spans. In this research, four slabs were tested under different combination of compartment fires. The details are:

For Slab B1: At 0 min, Compartment B was firstly exposed to fire. Then at $60 \mathrm{~min}$, Compartments A and C were simultaneously exposed to fire. At $180 \mathrm{~min}$, the nozzles in Compartment B were shut off, and those in Compartments $\mathrm{A}$ and $\mathrm{C}$ were simultaneously shut off at $235 \mathrm{~min}$. Each compartment was under fire (heating) about $175 \mathrm{~min}$. The test was stopped at $300 \mathrm{~min}$.

For Slab B2: The sequence of the three compartment fires was similar to that of Slab B1, but the time interval between Compartment $\mathrm{B}$ and Compartments $\mathrm{A}$ and $\mathrm{C}$ was $30 \mathrm{~min}$. Note that, at 160 min the heating was stopped for all three compartments. The reason is that the gap between Slab B2 and the furnace wall was formed due to the fall of mineral wool, and thus the fire escaped from the gap and burnt the string of the displacement transducers. To be safe, the heating was stopped earlier, and the furnace temperature was naturally cooled down to $400 \mathrm{~min}$ test time.

For Slab B3: Compartments A, B, C were sequentially exposed to fire. At 0 min, Compartment A 
was firstly exposed to fire. Then at $60 \mathrm{~min}$, Compartments B was fired and finally at $120 \mathrm{~min}$ Compartment $\mathrm{C}$ was under fire. In addition, the fire (heating) duration of each compartment was $180 \mathrm{~min}$. The test was stopped at $600 \mathrm{~min}$.

For Slab B4: Compartments A, C, B were sequentially exposed to fire and the time interval and the fire duration of each compartment were $60 \mathrm{~min}$ and $180 \mathrm{~min}$, respectively. The test was terminated at $600 \mathrm{~min}$.

\section{Experimental results and discussions}

This section discusses the experimental results for each slab, along with a brief explanation of the observed behaviours, including furnace temperatures, slabs' temperatures, deflections, corners' reaction forces, cracks and failure mode during both heating and cooling phases. In addition, the test results are discussed and compared with the results reported in the literatures.

\subsection{Thermal response}

\subsubsection{Furnace temperature}

The variation in the measured furnace temperatures with time during both the heating and cooling phases for four slabs is shown in Figs. 5-8. As indicated in the figures, the furnace temperatures measured at Points F-1, F-2 and F-3 in each compartment are similar to each other. For each test, the furnace temperature of the compartment, which was firstly exposed to fire, basically followed the ISO834 fire curve. For the adjacent compartments unexposed to fire, the furnace temperature also gradually increased due to the thermal conductivity of the refractory brick. For instance, for Slab B3 (see Fig. 7), at 60 (120) min, the average furnace temperature in Compartments A, B and C were $976{ }^{\circ} \mathrm{C}\left(1142{ }^{\circ} \mathrm{C}\right), 216{ }^{\circ} \mathrm{C}\left(1001^{\circ} \mathrm{C}\right)$ and $65{ }^{\circ} \mathrm{C}\left(405^{\circ} \mathrm{C}\right)$, respectively. Thus, the thermal properties of the refractory brick have an important effect on the furnace temperature of adjacent compartment during the early stage. On the other hand, as the adjacent compartments were ignited, the furnace temperatures rapidly increased until the shut-off time. Table 1 gives maximum furnace temperature, temperature at the shut-off time and temperature at the end of test for each compartment of the four tested slabs.

\subsubsection{Temperatures of the concrete slabs}

- Concrete temperatures

Figs. 9-12 show the temperature profiles along the thickness of the cross-sections of Slabs B1 to B4. As expected, the compartment temperature has considerable effect on the temperature distribution through the thickness of the slab within each compartment. Clearly, higher temperature gradient within the slab is due to the lower thermal conductivity and higher thermal capacity of 
concrete. In addition, there was a temperature plateau at about $100{ }^{\circ} \mathrm{C}$ near to the unexposed surfaces of the slab due to evaporation of free water.

The conventional one-dimensional thermal model may be used to predict the temperature field of the heated slabs [29-30]. However, it was observed that the temperatures near to the supports of the slabs were relatively lower due to the protection of the mineral wool. In this case, two dimensional heat transfer model needs to be used for accurately predicting the temperatures of unheated zones near the supports. Otherwise, the temperatures will be overpredicted [31]. In fact, as discussed in Refs. [18-20], the consideration of the realistic traveling fires is important for analysing the thermal and structural responses of the concrete floors. Table 2 gives the bottom and top concrete temperatures at the shut-off time of each compartment for the four tests. Note that, the shut-off time of each compartment is corresponding to the time that the nozzles of each compartment were closed, and thus each compartment had a different shut-off time.

- Rebar temperatures

Figs. 13-16 illustrate the temperature variations within the top and bottom reinforcing steel bars of the four slabs during heating and cooling stages. Similar to the concrete temperatures, the steel temperature within the each compartment was mainly depended on the corresponding furnace temperature. As expected, the top steel temperatures continued to increase for a certain time period after fire was shut down within the compartment. In addition, as shown in Fig. 16(c), for the Compartment C of Slab B4, the large temperature differences between Points B4-TC1-R-3 and B4-TC1-R-4 were due to the possible movements of the thermocouples during the concrete casting. Table 2 gives the bottom and top steel temperatures at the shut-off time of each compartment for the four tests.

\subsection{Deflection response}

This section discusses the vertical and horizontal deformations of the four tested concrete slabs during the heating and cooling phases. The measured deflections were plotted against time or furnace temperature, as shown in Figs. 17-21. In the figures, for vertical deflections, the negative displacement is downward and the positive displacement is upwards. For horizontal deformations, positive displacement is outward and negative displacement is inward.

\subsubsection{Vertical deflections}

- Vertical deflections-time curves

(1) Slabs B1 and B2

The central deflections of the three compartments for Slab B1 are shown in Fig. 17. It is noted that 
the central deflections of Compartments $\mathrm{A}$ and $\mathrm{C}$ are similar, but they are totally different compared to the central deflection of Compartment B. As shown in Fig. 17(b), during the first 60 min, the central deflection of Compartment B rapidly increased with time up to $-12.8 \mathrm{~mm}$ due to higher thermal gradient (see Fig. 9(b)).

Although Compartments $\mathrm{A}$ and $\mathrm{C}$ were not directly exposed to fire before $60 \mathrm{~min}$, their central deflections increased with time which were resulted from the thermal bowing of the slab and reached to $-6.0 \mathrm{~mm}$ and $-5.9 \mathrm{~mm}$, respectively at $60 \mathrm{~min}$, as shown in Figs. 17 (a) and (c). After 60 min, the central deflections of two edge Compartments A and C rapidly increased with similar trend, since they were simultaneously exposed to fire and had the same boundary conditions.

However, the central deflection of Compartment B changed the tendency to upward at approximately $60 \mathrm{~min}$ until $235 \mathrm{~min}$, which was resulted from the large downward central deflections of Compartments A and C. Similarly, at $235 \mathrm{~min}$, the deflections of Compartments A and $\mathrm{C}$ started to recover (upward) during the cooling stage, and thus the central deflection of Compartment $\mathrm{B}$ turned to downward again until the end of the fire test.

The test results indicate that the deflection of the slab within a fire compartment is not only based on that compartment fire temperature, but also is significantly affected by the fire in the adjacent fire compartments. Clearly, the similar observation can be obtained from the deflection behaviour of Slab B2 (Fig.18), although the test data were not recorded after $80 \mathrm{~min}$, due to the malfunction of the acquisition system.

\section{(2) Slab B3}

Figs. 19(a) to (c) show the central deflections of Slab B3 within three compartments against time. Different deflection trends of the three compartments in the slab indicated that the spreading sequence of a fire has important effects on the deflection behaviour of the slab within each compartment.

During the first $60 \mathrm{~min}$, the central deflection of the slab in Compartment A linearly increased with time due to high thermal gradients. For Compartment B, its central deflection firstly increased and then recovered at about $25 \mathrm{~min}$. At $60 \mathrm{~min}$, the central deflections of the slab in Compartments A and $\mathrm{B}$ were $-24.2 \mathrm{~mm}$ and $-2 \mathrm{~mm}$, respectively. Thus, during the early stage, the compartment temperature is the key factor to influence the deflection magnitude of the slab in that compartment, and the interaction between the heated compartment and its adjacent compartment is relatively strong.

As shown in Fig. 19, the central deflections of the slab in the three compartments have different 
trends between $60 \mathrm{~min}$ and $120 \mathrm{~min}$, due to more drastic moment redistribution. In addition, the two edge compartments (Compartments $\mathrm{A}$ and $\mathrm{C}$ ) have opposite overall deflection trends between $120 \mathrm{~min}$ and $300 \mathrm{~min}$, but their maximum deflections for both compartments were similar (such as $-29.31 \mathrm{~mm}$ and $-31.60 \mathrm{~mm}$ ) due to the same boundary conditions and fire duration. The comparison between Slabs B1, B2 and B3 indicates that for the various fire spreading scenarios, the concrete slabs with same loading and boundary conditions may have different deflection trend during the entire fire. However, as reported in Refs. [12-14], for the uniform fire, the slab panels with the same boundary condition often have the same deflection trends.

Compared to two edge compartments, Compartment B had complex deflection trend after 60 min, this is clearly due to the effect of the fire scenarios of two adjacent compartments. However, the absolute value of its maximum deflection (about $5 \mathrm{~mm}$ ) was clearly smaller than those of Compartments $\mathrm{A}$ and $\mathrm{C}$, although the fire duration was $180 \mathrm{~min}$. Thus, compared to the fire duration, the boundary condition and traveling fire scenario have more important effects on the maximum deflection of the middle compartment.

\section{(4) Slab B4}

For Slab B4, there are different deflection trends of the slab in the three compartments, as shown in Fig. 20. As expected, for Compartments A and C, their central deflections gradually increased with increasing temperatures. In addition, during the whole duration of the test, the deflection trend and the maximum deflection of Compartment $\mathrm{C}$ were similar to those of Compartment A. Hence, the comparison among Slabs B1 to B4 indicates that the maximum deflections of Compartments A and $\mathrm{C}$ were mainly dependent on the fire duration. This may be due to the fact that both compartments are edge compartments. Hence, the behaviour of the slab within the edge compartment is more similar to that of the simply supported slab.

At 120 min, Compartment B was exposed to fire and its upward central deflection continued to increase until the fire in Compartment A was shut-off. The upward deflection trend of Compartment B during the entire fire test was mainly due to the hogging bending moments generated at the continuous slabs over both supports between Compartments B and A and Compartments B and C. More importantly, compared to other traveling fire scenarios, this case tends to lead to larger vertical deflection of the middle compartment. It can be seen that the maximum deflection of the middle compartment was mainly dependent on the fire sequence or spread direction.

As shown in Fig. 20 (b), the maximum upward deflection in the Compartment B was $24.16 \mathrm{~mm}$ which is much great than Slab B3 (see Fig. 19(b)). This is due to the fact that the top reinforcing 
steel layers of Slab B4 are discontinuous over the slab in central areas of the compartments (see Fig. 2(c)). Hence, the hogging bending stiffness of the slab in the central area of Compartment B was much less compared to Slab B3. Also a large main crack was formed across Compartment B. This integrity failure of Slab B4 mainly resulted from the discontinuous arrangement of the top reinforcement layers. Therefore, for fire resistant design, it is important to utilise the continuous top reinforcing arrangement for the floor.

- Deflection versus average furnace temperature curves

Figs. 21(a)-21(d) show the central deflection of each compartment versus average compartment temperature curves for Slabs B1 to B4. It is evident from the figures that for Compartments A and C in each tested slab, the curves show a clear heating and cooling stages. During the heating stage when the compartment temperature was less than $600{ }^{\circ} \mathrm{C}$, the central deflections of Compartments $\mathrm{A}$ and $\mathrm{C}$ were relatively small. After the compartment temperature was greater than $600{ }^{\circ} \mathrm{C}$, the central deflections rapidly increased. The deflection behaviour of the slabs were similar to simply support or continuous slabs under uniform fire, observed in previous fire tests [7-10]. However, for Compartment $\mathrm{B}$, the deflection-furnace temperature curve was relatively complex. Its deflection behaviours were affected by the deformations and fire scenarios of adjacent compartments.

\subsubsection{Horizontal displacements}

Figs. 22(a)-22(d) show the measured horizontal (in-plane) displacements at Points H1, H2, H3 and $\mathrm{H} 4$ for the four concrete slabs. The horizontal displacements of the slabs were mainly due to the thermal expansion. The horizontal displacements of Points $\mathrm{H} 1$ and $\mathrm{H} 3$ were generally larger than those of Points $\mathrm{H} 2$ and $\mathrm{H} 4$, since Points $\mathrm{H} 1$ and $\mathrm{H} 3$ measured the thermal expansion along the long span (west-east) direction of the slab. It is evident that the magnitude of the horizontal displacements was mainly affected by the fire scenarios of compartments. The contraction displacements tended to occur in each measured point after the fires in all compartments were shut-off. The maximum horizontal displacements of Slabs 1 to 4 were $8.99 \mathrm{~mm}, 9.72 \mathrm{~mm}, 9.01 \mathrm{~mm}$ and $13.63 \mathrm{~mm}$, respectively. Clearly, compared to the central vertical deflection of each compartment, the horizontal displacement at each point is relatively large.

\subsection{Corners' restraint forces}

In this section, the reaction forces at the four corners of each slab are briefly discussed. In the figures positive forces represent the compressive forces during each test.

(1) Slabs B1 and B2

Fig. 23(a) shows the reaction forces measured by the four pressure sensors at Points P-1 to P-4 (see 
Fig. 3). It can be seen that four reaction force-time curves in Slab B1 had similar overall trends during the fire test. This is due to the same boundary condition and the symmetrical fire sequence.

The variation of corners forces at each position during and after fire exposure can be grouped into three stages, i.e., the ascending stage, the steady stage and the descending stage. During the first stage (from the start of fire to about $100 \mathrm{~min}$ ), the four corners' forces increased with time. This was mainly caused by the increasing deflections of the slab in two edge compartments. During the second stage (from about $100 \mathrm{~min}$ to $180 \mathrm{~min}$ ), four corners' forces were basically kept at a steady value with the maximum values of $4.8 \mathrm{kN}, 9.38 \mathrm{kN}, 6.52 \mathrm{kN}$ and $7.64 \mathrm{kN}$ for Point P-1 to Point P-4, respectively. Similar to those reported in Refs. [9-10], the magnitude of the corners' reaction forces was mainly dependent on the number of cracks formed near the corners. In the third stage (from $180 \mathrm{~min}$ to $300 \mathrm{~min}$ ), the corners' reaction forces decreased with time due to the deflection recover of Compartments $\mathrm{A}$ and $\mathrm{C}$. It can be seen that the whole trend of the reaction forces was mainly dependent on the deflection behaviour of the corresponding compartments.

The variation of corners' forces of Slab B2 is plotted in Fig. 23(b) as a function of fire exposure time. Clearly, due to similar fire sequence, the reaction force trend of Slab B2 was similar to that of Slab B1 and can be also divided into three stages. Note that, the forces at Points P-1 to P-4 reached the maximum values of $3.65 \mathrm{kN}, 10.56 \mathrm{kN}, 4.97 \mathrm{kN}$ and $3.54 \mathrm{kN}$ at $96 \mathrm{~min}, 112 \mathrm{~min}, 107 \mathrm{~min}$ and 76 min, respectively. Compared to Slab B1, its maximum reaction forces in Slab B2 appeared earlier due to the smaller delay time (30 min).

(2) Slabs B3 and B4

The variation of the corners reaction forces of Slabs B3 and B4 is plotted in Figs. 23(c) and 23(d) as a function of fire exposure time. As expected, the reaction force-time curves of the four corners of Slabs B3 and B4 were different from those of Slabs B1 and B2 (Figs. 23(a) and 23(b)). It is evident that the fire sequence is a key factor influencing the reaction force trend.

On one hand, as shown in Fig. 23(c), the reaction force-time curves at Points P-3 and P-4 had two stages, i.e., the ascending and descending stages, but the curves at Points P-1 and P-2 had three stages, i.e., level-off stage, ascending and descending stages. In addition, the maximum reaction forces of Points P-1 to P-4 were $6.4 \mathrm{kN}, 9.88 \mathrm{kN}, 7.89 \mathrm{kN}$ and $9.63 \mathrm{kN}$, respectively, with the average value of $8.45 \mathrm{kN}$. It can be seen that due to fewer corners' cracks, its average value was higher than those of Slabs B1 $(7.09 \mathrm{kN})$ and B2 $(5.68 \mathrm{kN})$.

As shown in Fig. 23(d), the reaction forces at Points P-1 and P-2 were very small and kept unchanged before the fire in Compartment $\mathrm{C}$ was ignited. This means that the fire scenario of one edge compartment has little effect on the corners reaction force of another edge compartment. 
However, as Compartment B was ignited, the reaction forces of all four points gradually decreased with time until the end of the fire test. In addition, the average value of the maximum reaction forces was $4.96 \mathrm{kN}$ and smaller than those of the another three slabs. The comparison shows that for the continuous slab, the reaction force trend of one corner was dependent on the fire scenario of its compartment and the adjacent compartment.

According to the above results, it was found that for any fire sequence, the sudden increase or decrease of the corner forces did not occur because the tested slabs were reinforced with top reinforcing steel layers, and the trend was relatively smooth. In addition, the corners' reaction force trend of each point was mainly dependent on the sequence of different compartment fire, and the corresponding maximum value of the reaction forces often appeared when all three compartments were subjected to fire.

\subsection{Structural failures}

\subsubsection{Observations}

During the fire test, the four concrete slabs were inspected for the test phenomena. After the test, visual signs of cracking and spalling were investigated and photographic evidence of the failure mode is presented in this paper.

\section{(1) Slab B1}

As shown in Fig. 5, Compartment B was firstly exposed to fire. At about 27 min, water steam was emitted from top surface of the slab in Compartment B and gradually increased with time. At 44 min, the south-north short-span cracks were seen on the unexposed surface at the two intermediate supports and middle region of Compartment B. At $60 \mathrm{~min}$, Compartments A and C were simultaneously exposed to fire, and no water steam appeared on top surface of Compartment B. Between $80 \mathrm{~min}$ and $90 \mathrm{~min}$, the steam and several cracks appeared on the top surfaces of Compartments A and C. Meanwhile, a large amount of water and steam also seeped through the cracks until to $120 \mathrm{~min}$. Note that, no spalling was heard from the bottom surface of the slab. This is because the slab has had about 2 years of drying before the test.

Figs. 24(a)-24(b) show the top view of Slab B1 after the fire. Cracks were darkened with a brush to make them visible in the photograph. Clearly, many cracks parallel to south-north (short-span) directions could be seen on the top surface of the slab within each compartment. In addition, there 
were several long cracks in west-east direction in the slab within each compartment. Clearly, these two-way cracking patterns are different from those of one-way continuous slabs observed in Refs. [32-33].

Figs. 24(c)-24(d) show the bottom view of the slab after the fire. Some diagonal cracks running at $45^{\circ}$ from the corners and some cracks normal to the edges could also be seen on the bottom surface, but no cracks appeared on the middle region of each compartment. Thus, the integrity failure did not occur in the slab. In addition, the bottom steel was not seen, although the concrete spalled on the bottom surface.

In all, there were different cracking patterns on the top surfaces of Slab B1 within three compartments. The cracking pattern of the slab in Compartments $\mathrm{A}$ and $\mathrm{C}$ were similar to each other due to the same fire and boundary conditions. But, the cracks on the top surface of the slab in Compartment $\mathrm{B}$ were relatively much more due to large hogging bending moment at two continuous supports. In addition, many cracks located near to two continuous supports.

(2) Slab B2

For Slab B2, the fire process was similar as that of Slab B1. As shown in Fig. 6, Compartment B was firstly exposed to fire. At $20 \mathrm{~min}$, the steam appeared on the top surface of the slab within Compartment B, the amount of steam increased with increasing furnace temperature. At approximately $30 \mathrm{~min}$, Compartments $\mathrm{A}$ and $\mathrm{C}$ were simultaneously exposed to fire, and the steam gradually appeared on the top surfaces of the slabs in two edge compartments at $40 \mathrm{~min}$. At approximately $50 \mathrm{~min}$, the slab in Compartment B deformed upward, and a large amount of steam appeared on Compartments A and C. After that, the north-south direction cracks appeared near to the two intermediate supports due to the hogging bending moment (see Fig. 25). With increasing furnace temperature, cracks on the unexposed surface of the slab spread from intermediate supports towards the central regions of the compartments, and these cracks were widen. At approximately 90 min, the steam became weaker at Compartment B, but a lot of steam still vapored from Compartments A and C. At 125 min, the top surface of the slab in each compartment was dry. At $160 \mathrm{~min}$, for considering safety, the test was terminated. In addition, no concrete spalling was heard during the test.

Figs. 25(a)-25(d) show the cracking patterns on the top and bottom surfaces of the slab after the test. The comparison between top surfaces of Slabs B1 and B2 indicates that the cracking patterns 
of the slabs within corresponding compartments are similar to each other. However, there are the obvious differences on the bottom surfaces of the two slabs. Compared to Slab B1, there was no concrete spalled from the bottom surface of Slab B2. Also several north-south cracks across the whole short span appeared on the bottom surface of the slab within Compartment B. This indicated that the through thickness cracks were formed and the integrity failure occurred. Note that, based on the cracking patter of the slab within Compartment B, the slab in Compartment B was subjected to one-way bending.

\section{(3) Slab B3}

As shown in Fig. 7, for Slab B3, Compartments A, B and C were successively exposed to fire with the time interval of $60 \mathrm{~min}$. Similar to Slabs B1 and B2, at $30 \mathrm{~min}$, the steam and small cracks appeared on the top surface of the slab in Compartment A. After 40 min, a large amount of steam appeared, and the cracks formed on the internal support between Compartments A and B. At 60 min, Compartment B was exposed to fire, and then many small cracks appeared on the slab in Compartment B. With increasing furnace temperature, the crack width increased with large amount of the steam. At about 100 min, the cracks formed on the support between Compartments B and C. At about 110 min, the top surface of the slab in Compartment A was dry. After Compartment C was exposed to fire, a lot of cracks on top surface of the slab in Compartment $\mathrm{C}$ appeared, and the slab in Compartment B was dry at $150 \mathrm{~min}$. Meanwhile, the number and width of cracks gradually increased on the top surface of the slab in Compartment $\mathrm{C}$.

The cracking pattern on the top and bottom surfaces of Slab B3 after the test was shown in Figs. 26(a)-26(d). Compared to Slabs B1 and B2, the cracks' width on the top surface of Slab B3 was much smaller. This is due to the smaller steel spacing with higher reinforcement ratio. Hence, increasing the reinforcement ratio is beneficial to enhance the fire resistant of the slab, particularly to prevent the integrity failure. This conclusion is similar to the observation in Ref. [9]. For the bottom surface, the cracking pattern is similar to that of Slab B1, and the concrete on the bottom surface of the slab in Compartment C spalled.

\section{(4) Slab B4}

As shown in Fig. 8, Compartments A, C and B were successively exposed to fire with the time interval of $60 \mathrm{~min}$. Similar to other tested slabs, after about $30 \mathrm{~min}$, the steam appeared on the top 
surface of the slab in Compartment A, and the cracks also appeared on the support between Compartments A and B and the middle region of Compartment A. The steam gradually increased and the cracks' width also increased with heating time. At $60 \mathrm{~min}$, Compartment $\mathrm{C}$ was exposed to fire, and then the cracks appeared in the central area of the compartment at $70 \mathrm{~min}$. At $90 \mathrm{~min}$, the steam appeared in the slab within Compartment C. Noted that, an amount of steam also appeared on the slab in Compartment B which was not directly exposed to fire. At about 105 min, the slab in Compartment A was dry, but a large amount of steam appeared on the top surface of the slab in Compartment C. This observation is similar to the conclusion discussed in Refs. [33-34] that the steam behaviour can be considered to provide the evidence for judging the fire stage of each compartment.

As shown in Fig. 20, before $120 \mathrm{~min}$, the downward deflection appeared on the slabs in Compartments A and C, but the slab in Compartment B had the upward deflection trend (see Fig. 27(a)). As shown in Figs. 27(b)-27(d), one main crack (red arrow in Figs. 27(c) and 27 (d)) appeared near to the truncation of the top layer reinforcement within the slab of Compartment B, and its crack width was about $10 \mathrm{~mm}$. At $120 \mathrm{~min}$, Compartment B was exposed to fire, the width of the main crack further increased. At 146 min, Compartment C was dry, but a large amount of steam appeared on Compartment B. At $180 \mathrm{~min}$, there was no steam on the top surface of the slab. Meanwhile, the width of the main crack on the top surface of the slab in Compartment B was about $20 \mathrm{~mm}$. This failure mode was resulted from the hogging bending moment acting on the slab in Compartment B. In addition, no spalling was found on the bottom surface of the slab.

Figs. 27(c)-27(f) show the cracking pattern of the top and bottom surfaces of Slab B4 after the test. As expected, cracking patterns of the slabs in Compartments $\mathrm{A}$ and $\mathrm{C}$ were similar to each other, but they were different from the slab in Compartment B. In addition, due to the larger spacing and discontinuous of top layer reinforcement, many large cracks appeared on the top surface of the slab. Hence, to enhance the fire resistance of the slab, continuous top layer reinforcement should be used.

\subsubsection{Discussion}

According to the tested results of four slabs, the main failure pattern of the tested slabs is the typical transverse cracks formed on the top surface of the slabs within the edge and middle compartments. 
The main reason is that the hogging moment generates the tensile stress on the top surface of the slab, particularly in the middle compartment. In addition, the middle compartment had sufficient thermal expansion restraint from two edge compartments. In this case, compared to the two edge compartments, the integrity failure tends to occur in the slab within the middle compartment. For the bottom surface of the slabs, many short cracks appeared around four edges of the slabs. This is due to the fact that the concrete temperature near to the edge of the slab was lower than that of its middle region, and thus the in-plane temperature difference led to the tensile stresses.

Apart from the boundary condition, the failure modes of the slabs were considerably influenced by the reinforcement ratio and its arrangement. For any fire scenario, higher reinforcement ratio and continuous reinforcing bars were beneficial to avoid the larger short-span cracks, particularly for the slabs above two internal supports and within Compartment B. Meanwhile, the distance between cracks became smaller with increasing reinforcement ratio. The reason is that the higher reinforcement ratio avoids a large localized crack formed within the concrete.

From the test results it is evident that the behaviour of the continuous slab under spreading fire is considerably different compared to those of the isolated slabs or the continuous slabs subjected to uniform fire. The mid-span deflection of each compartment in the continuous slab subjected to spreading fire was mainly affected by the extended total fire duration, fire spread direction and time delay. For each compartment, its maximum vertical deflection during the entire fire was mainly dependent on itself fire duration, but the fire spread direction and time delay have criterial effects on its deflection trend, particularly in the middle compartment.

In all, the test results indicate that the structural response of the continuous slab can be influenced by many factors. They include but are not limited to, for example, boundary conditions, travelling fire type (fire spread direction, time delay, changing location of fire and fire temperature), reinforcement ratio and reinforcement layout, etc. Thus, for the same concrete slabs, the traveling fire and uniform fire may lead to substantially different structural responses, which is important in the structural fire design of the concrete slabs. One single worst case fire scenario cannot be readily identified, considering the uncertainty of fire and the complexity of structural response. Finally, it can be concluded that the conventional limit capacity methods [35-41] based on the simply 
supported concrete slabs and the failure criteria based on the temperature or deflection cannot be directly applicable in the fire resistant design of the continuous slabs subjected to spreading fire.

\section{Conclusions}

In this paper four fire tests on the three-span continuous reinforced concrete floor slabs under different compartment fires are presented. Based on the experimental results, following conclusions can be drawn:

(1) The temperature distribution of the slab in each compartment was mainly dependent on the fire temperature within that compartment. However, it was slightly influenced by the fire temperature of adjacent compartments

(2) For continuous floor slab, the central vertical deflection of the slab in the middle compartment was considerably affected by the vertical deflections of the slabs in two edge compartments. The key factor is the rotational stiffness of the slab over the continuous supports in which the top layer reinforcement over the supports plays a key role. In addition, for one continuous slab, its nonlinear horizontal deformation was dependent on the fire scenario of any compartment, and the horizontal deflection tended to increase with the time as long as one compartment was exposed to fire.

(3) The corners' reaction force of one compartment in the continuous slab was mainly dependent on the deflection trend, the fire scenario of its compartment and the top layer reinforcing bars.

(4) The boundary condition, the ratio and arrangement of top reinforcement of the continuous slab, and fire spreading scenarios have important effects on the failure mode of the slabs in different compartments. It is evident that more severe cracking happened within the slab in middle compartment compared to two edge compartments. For the edge compartment, the slab may fail due to large deflection and the integrity failure of the slab within the middle compartment may occur. Increasing reinforcement ratio and using the continuous reinforcement are effective methods to prevent or delay the failure of the continuous slabs with any fire spreading scenarios.

(5) The conventional limit capacity methods or failure criteria for simply supported concrete slabs cannot be directly applied to the fire resistant design of the continuous slabs subjected to spreading fire. 


\section{Acknowledgements}

This research was supported by the Fundamental Research Funds for the Central Universities (Grant No. 2019XKQYMS32). The authors gratefully acknowledge this support.

\section{References}

[1] Lin TD, Zwiers RI, Shirley ST, Burg RG. Fire test of concrete slab reinforced with epoxy-coated bars. ACI Struct J 1989;86:156-62.

[2] Lim L, Wade C. Experimental fire tests of two-way concrete slabs. In: Fire engineering research report 02/12. New Zealand: University of Canterbury and BRANZ Ltd; 2002.

[3] Lim L, Buchanan A, Moss P, Franssen JM, Numerical modelling of two-way reinforced concrete slabs in fire. Eng Struct, 2004;26:1081-91.

[4] Bailey CG, Toh WS. Behaviour of concrete floor slabs at ambient and elevated temperatures. Fire Saf J 2007;42:425-36.

[5] Bailey CG, Toh WS. Small-scale concrete slab tests at ambient and elevated temperatures. Eng Struct 2007;29:2775-91.

[6] Lim L, Buchanan A, Moss P, Franssen JM. Computer modeling of restrained reinforced concrete slabs in fire conditions. J Struct Eng 2004;130:1964-71.

[7] Wang B and Dong YL. Experimental study of two-way reinforced concrete slabs under fire. China Civil Eng J 2010;43:53-62 [in Chinese].

[8] Dong YL and Zhu CJ. Limit load carrying capacity of two-way slabs with two edges clamped and two edges simply supported in fire. J Struct Eng 2010;137:1182-92.

[9] Wang Y, Yuan GL, Huang Z, et.al, Experimental study on the fire behaviour of reinforced concrete slabs under combined in-plane and out-of-plane loads. Eng Struct 2016;128:316-32.

[10] Wang Y, Luke AB, Wang TY, et al. Fire behaviour of reinforced concrete slabs under combined biaxial in-plane and out-of-plane loads. Fire Saf J 2018, 96:27-45.

[11] L.G. Chen, The experimental research of reinforced concrete slab. PhD Thesis, J. Xi'an Univ. of Arch. \& Tech, China, 2004 [in Chinese]. 
[12] Yang ZN, Dong YL, Xu WJ. Fire tests on two-way concrete slabs in a full-scale multi-storey steel-framed building. Fire Saf J 2013;58: 38-48.

[13] Wang Y, Dong YL, Li B, Zhou GC. A fire test on continuous reinforced concrete slabs in a full-scale multi-story steel-framed building. Fire Saf J 2013;61:232-42.

[14] Li B, Dong Y, Lou YJ. A fire test of continuous panels in a full-scale steel-framed structure. Eng Mech 2015;32:145-53 [in Chinese].

[15] Bailey CG, Moore DB. The structural behaviour of steel frames with composite floors slabs subject to fire-part 1 theory. Struct Eng 2000;78 (11):19-27.

[16] Stern-Gottfried J, Rein G. Travelling fires for structural design-Part I: Literature review. Fire Saf J 2012;54:74-85.

[17] Stern-Gottfried J, Rein G. Travelling fires for structural design-Part II: Design methodology. Fire Saf J 2012;54:96-112.

[18] Rackauskaite E, Hamel C, Law A, Rein G. Improved formulation of travelling fires and application to concrete and steel structures. Structures 2015;3:250-60.

[19] Law A, Stern-Gottfried J, Gillie M, Rein G. The influence of travelling fires on a concrete frame. Eng Struct 2011;33:1635-42.

[20] Rackauskaite E, Kotsovinos P, Rein G. Structural response of a steel-frame building to horizontal and vertical travelling fires in multiple floors. Fire Saf J 2017;91:542-52.

[21] Code for design of concrete structures (GB50010-2010). Beijing; 2010 [in Chinese].

[22] GB/T 51231-2016. Technical standard for assembled buildings with concrete structure. Beijing: China Architecture \& Building Press, 2017. [In Chinese].

[23] Load code for the design of building structures (GB50009-2001). Beijing; 2006 [in Chinese].

[24] Standard Methods for Testing of Concrete Structures of China (GB50152-92). Beijing; 1992 [in Chinese].

[25] C Röben, M Gillie, J L Toreo. Structural behaviour of during a vertically traveling fire. J Constr Steel Res 2010; 66: 191-197. 
[26] Code for fire protection design of buildings (GB 50016-2014). Beijing; 2018 [in Chinese].

[27] C G Bailey, I W Burgess, R J Plank. Analyses of the effects of cooling and fire spread on steel-framed buildings, Fire Saf J 1996; 26: 273-293.

[28] E Ellobody, C G Bailey. Structural performance of a post-tensioned concrete floor during horizontally travelling fires. Eng Struct 2011; 33: 1908-1917.

[29] Huang Z, The behaviour of reinforced concrete slabs in fire. Fire Saf J 2010; 45:271-82.

[30] Kodur VKR, Bisby L. Evaluation of fire endurance of concrete slabs reinforced with fiber-reinforced polymer bars. J Struct Eng 2005;131:34-43.

[31] Hajiloo H, Green MF, Noël M, et al. Fire tests on full-scale FRP reinforced concrete slabs. Compos Struct 2017;179:705-19.

[32] Hou XM, Zheng WZ, Kodur VKR. Response of unbonded prestressed concrete continuous slabs under fire exposure. Eng Struct 2013;56:2139-48.

[33] Yuan AM, Dong YL, Gao LT. Behavior of unbonded prestressed continuous concrete slabs with the middle and edge span subjected to fire in sequence. Fire Saf J 2013;56: 20-29.

[34] Li LZ, Liu X, Yu JT, et al. Experimental study on seismic performance of post-fire reinforced concrete frames. Eng Struct 2019; 179:161-173.

[35] Omer E, Izzuddin BA, Elghazouli AY. Failure of unrestrained lightly reinforced concrete slabs under fire, Part I: Analytical models. Eng Struct 2010;32:2631-46.

[36] Li GQ, Guo SX, Zhou HS. Modeling of membrane action in floor slabs subjected to fire. Eng Struct 2007;29:880-7.

[37] Dong YL, Fang YY. Determination of tensile membrane effects by segment equilibrium. Mag Concr Res 2010;62(1):17-23.

[38] Cashell KA, Elghazouli AY, Izzuddin BA. Failure assessment of lightly reinforced floor slabs II: Analytical studies. J Struct Eng 2011; 137: 989-1001.

[39] Herraiz B, Vogel T. Novel design approach for the analysis of laterally unrestrained reinforced concrete slabs considering membrane action. Eng Struct 2016; 123 :313-29. 
[40] Burgess I. Yield line plasticity and tensile membrane action in lightly-reinforced rectangular concrete slabs. Eng Struct 2017; $138: 195-214$.

[41] Wang Y, Zhang YJ, Huang ZH, Bisby L. New analytical method for determining the load-carrying capacity of two-way simply supported concrete slabs. Adv Struct Eng 2018; 2:1-16. 


\section{Table and Figure Captions}

Table 1 Furnace temperatures of four tested slabs

Table 2 Concrete and steel temperatures of four tested slabs at the shut-off time of each compartment

Fig. 1 Self-designed furnace (all dimensions in $\mathrm{mm}$ )

Fig. 2 The details of reinforcing steel within four slabs (all dimensions in $\mathrm{mm}$ )

Fig. 3 Loading device, supports on the furnace wall and corners' restraint (all dimensions in $\mathrm{mm}$ )

Fig. 4 Thermocouple location and displacement transducers for each tested slab (all dimensions in $\mathrm{mm})$

Fig. 5 Furnace temperature-time curves of Slab B1

Fig. 6 Furnace temperature-time curves of Slab B2

Fig. 7 Furnace temperature-time curves of Slab B3

Fig. 8 Furnace temperature-time curves of Slab B4

Fig. 9 Temperature distributions along the thickness of Slab B1

Fig. 10 Temperature distributions along the thickness of Slab B2

Fig. 11 Temperature distributions along the thickness of Slab B3

Fig. 12 Temperature distributions along the thickness of Slab B4

Fig. 13 Temperatures of the reinforcing steels of Slab B1

Fig. 14 Temperatures of the reinforcing steels of Slab B2

Fig. 15 Temperatures of the reinforcing steels of Slab B3

Fig. 16 Temperatures of the reinforcing steels of Slab B4

Fig. 17 Vertical deflections-time curves of Slab B1

Fig. 18 Vertical deflections-time curves of Slab B2

Fig. 19 Vertical deflections-time curves of Slab B3 
Fig. 20 Vertical deflections-time curves of Slab B4

Fig. 21 Vertical deflections-average furnace temperature curves of: (a) Slab B1, (b) Slab B2, (c) Slab B3 and (d) Slab B4.

Fig. 22 Horizontal deflections-time curves of four slabs: (a) Slab B1, (b) Slab B2, (c) Slab B3 and (d) Slab B4

Fig. 23 Restraining forces at the corners of four slabs: (a) Slab B1, (b) Slab B2, (c) Slab B3 and (d) Slab B4

Fig. 24 Failure modes of Slab B1: (a) cracking pattern on the top surface, (b) crack development, (c) bottom surface and (d) cracking pattern on the bottom surface

Fig. 25 Failure modes of Slab B2: (a) cracking pattern on the top surface, (b) crack development, (c) bottom surface and (d) cracking pattern on the bottom surface

Fig. 26 Failure modes of Slab B3: (a) cracking pattern on the top surface, (b) crack development, (c) bottom surface and (d) cracking pattern on the bottom surface

Fig. 27 Failure modes of Slab B4: (a) upward deflection behaviour of Compartment B, (b) main crack, (c) cracking pattern on the top surface, (d) crack development, (e) bottom surface and (f) cracking pattern on the bottom surface 
Tables:

Table 1 Furnace temperatures of four tested slabs

\begin{tabular}{ccccc}
\hline \multirow{2}{*}{ Slab } & Compartment & \multicolumn{3}{c}{ Average furnace temperature $\left({ }^{\circ} \mathrm{C}\right)$} \\
\cline { 3 - 5 } & & Maximum furnace temperature & $\begin{array}{c}\text { Temperature at the shut-off } \\
\text { time }\end{array}$ & $\begin{array}{c}\text { Temperature at the } \\
\text { end of test }\end{array}$ \\
\hline \multirow{2}{*}{ B1 } & A & 1198 & 998 & 491 \\
& B & 1112 & 1096 & 555 \\
& C & 1133 & 1015 & 491 \\
B2 & A & 1188 & 958 & 300 \\
& B & 1016 & 873 & 360 \\
& C & 1299 & 1104 & 340 \\
B3 & A & 1150 & 1142 & 332 \\
& B & 1200 & 1200 & 401 \\
& C & 1249 & 1238 & 367 \\
B4 & A & 1150 & 1141 & 295 \\
& B & 1127 & 1127 & 348 \\
\hline
\end{tabular}

Table 2 Concrete and steel temperatures of four tested slabs at the shut-off time of each compartment

\begin{tabular}{cccccc}
\hline \multirow{2}{*}{ Slab } & \multirow{2}{*}{ Compartment } & \multicolumn{2}{c}{ Concrete $\left({ }^{\circ} \mathrm{C}\right)$} & \multicolumn{2}{c}{ Steel $\left({ }^{\circ} \mathrm{C}\right)$} \\
\cline { 3 - 6 } & & Bottom surface & Top surface & Bottom & Top \\
\hline \multirow{2}{*}{ B1 } & A & 876 & 192 & 666 & 310 \\
& B & 742 & 272 & 646 & 290 \\
& C & 877 & 238 & 672 & 312 \\
B2 & A & 1007 & 94 & 677 & 213 \\
& B & 829 & 126 & 624 & 222 \\
& C & 996 & 173 & 706 & 285 \\
B3 & A & 851 & 184 & 605 & 263 \\
& B & 1130 & 201 & 712 & 331 \\
& C & 941 & 200 & 660 & 291 \\
B4 & A & 671 & 142 & 529 & 312 \\
& B & 903 & 265 & 644 & 360 \\
& C & 890 & 196 & 627 & 303 \\
\hline
\end{tabular}




\section{Figures}

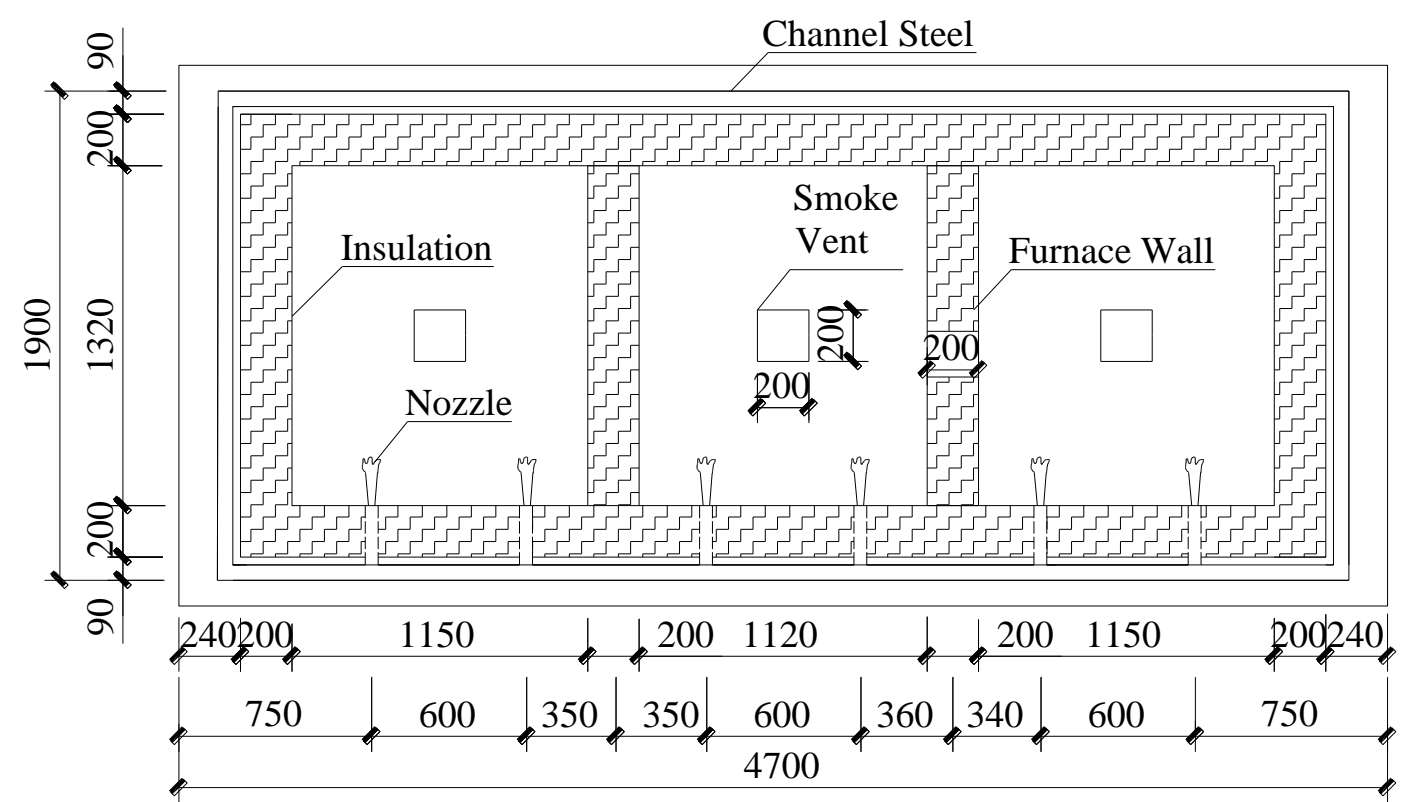

(a) Plan view of the self-designed furnace

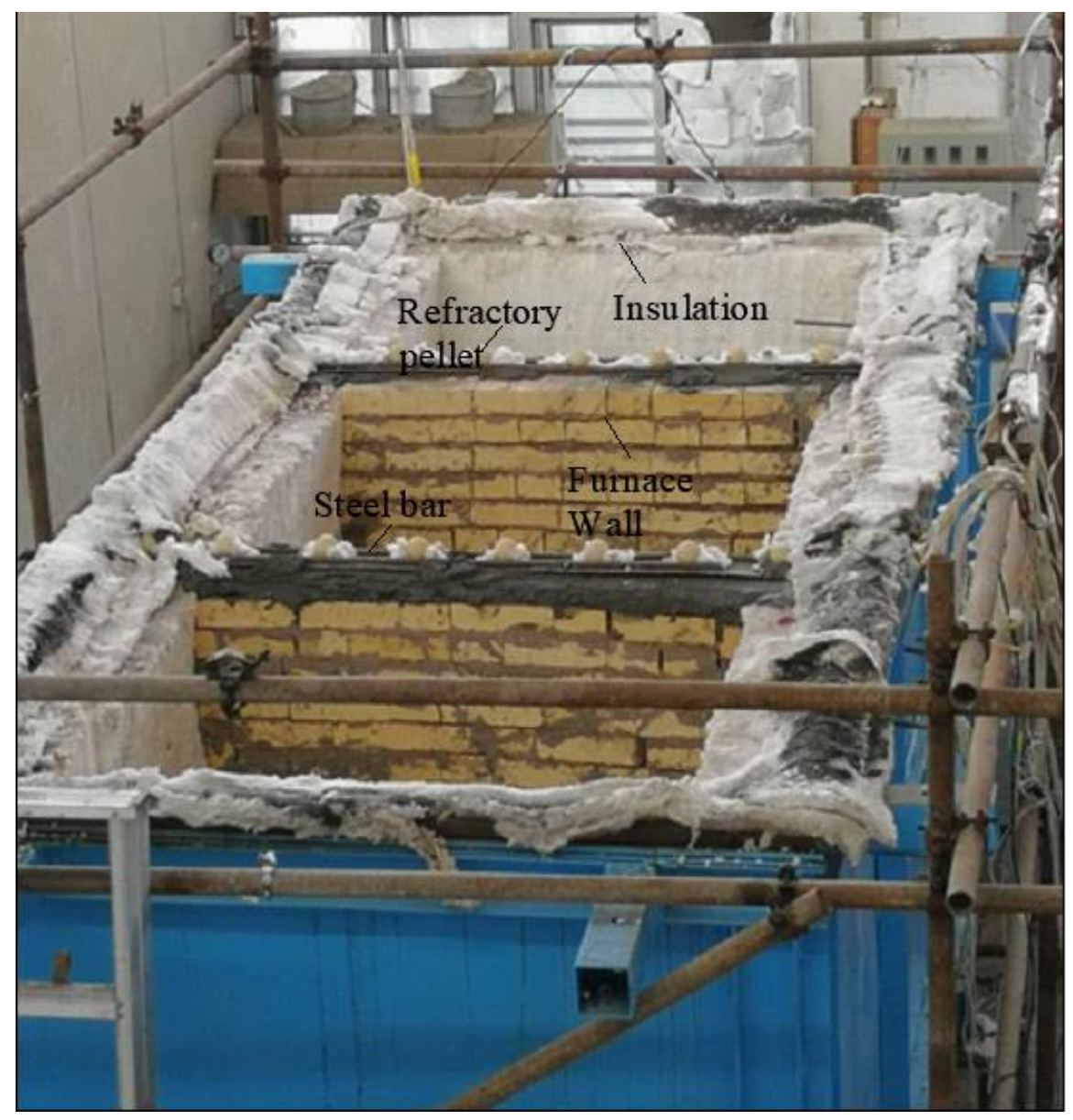

(b) Photograph of the internal wall 


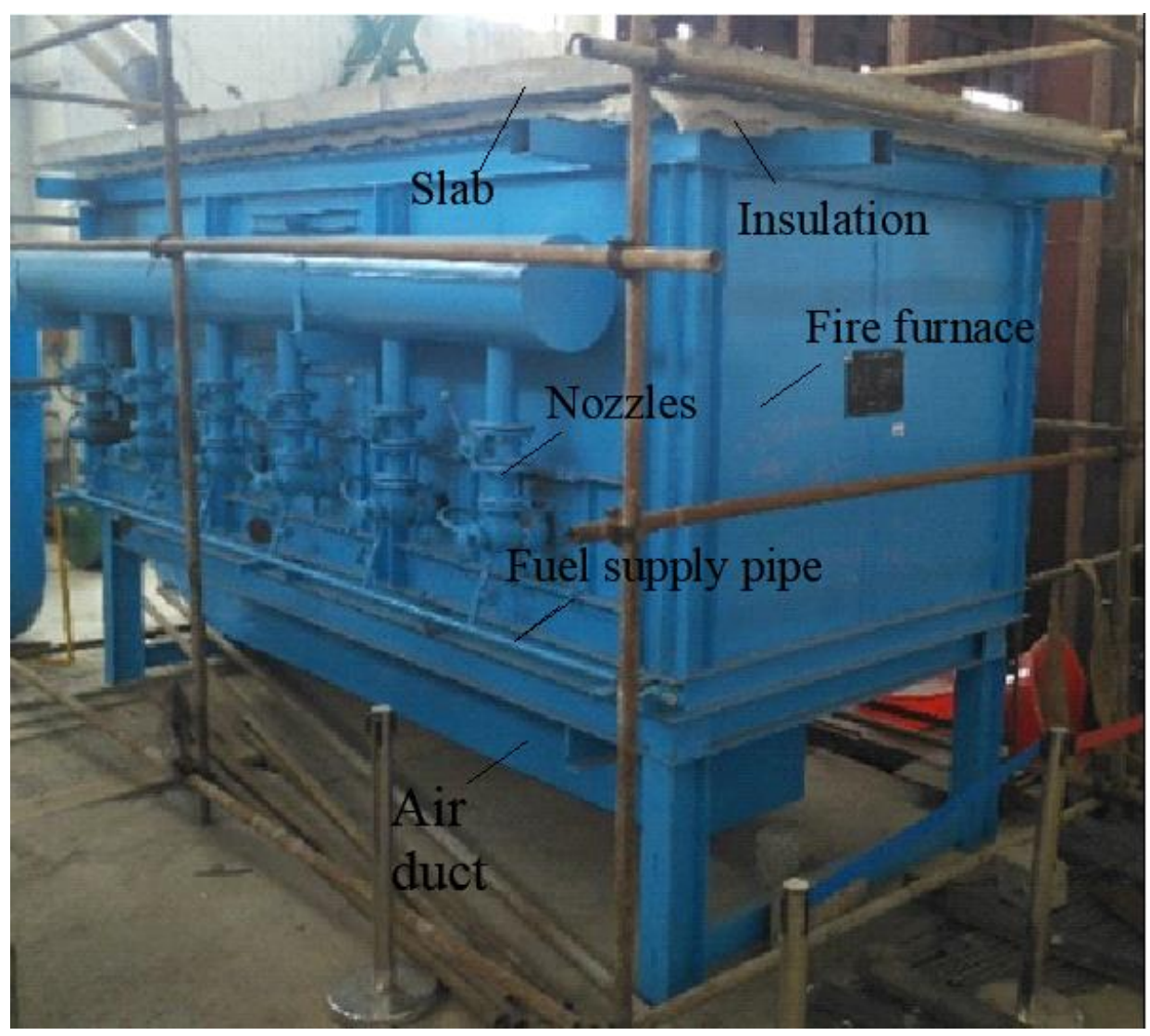

(c) Photograph of the self-designed furnace

Fig. 1 Self-designed furnace (all dimensions in $\mathrm{mm}$ ) 


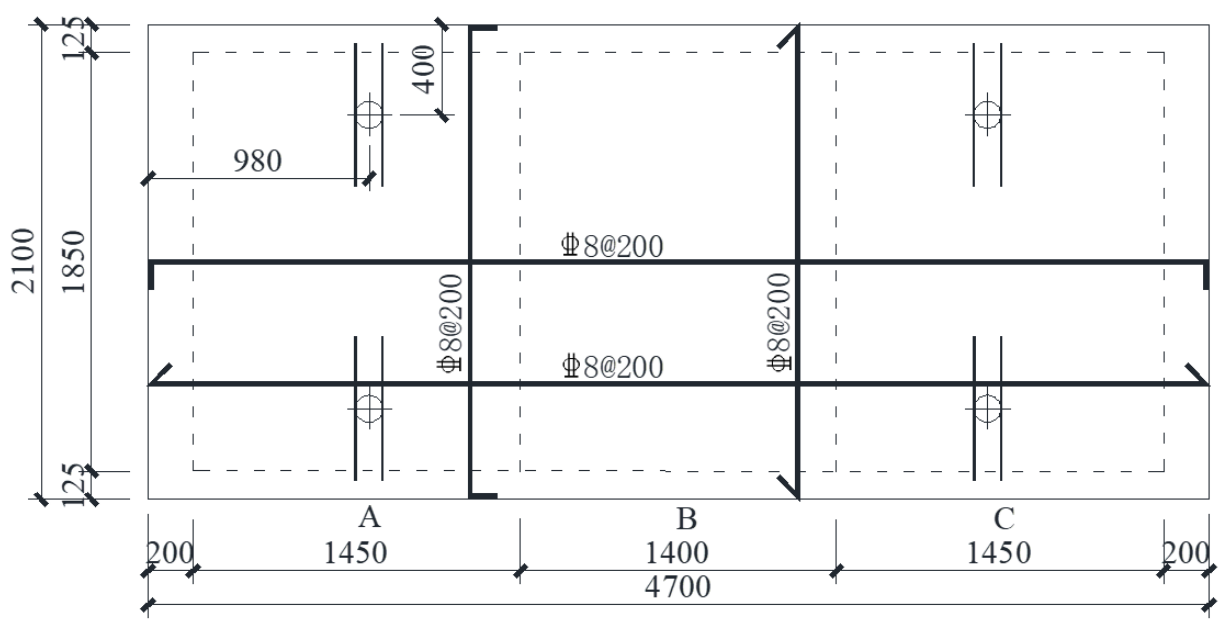

(a) Slabs B1 and B2

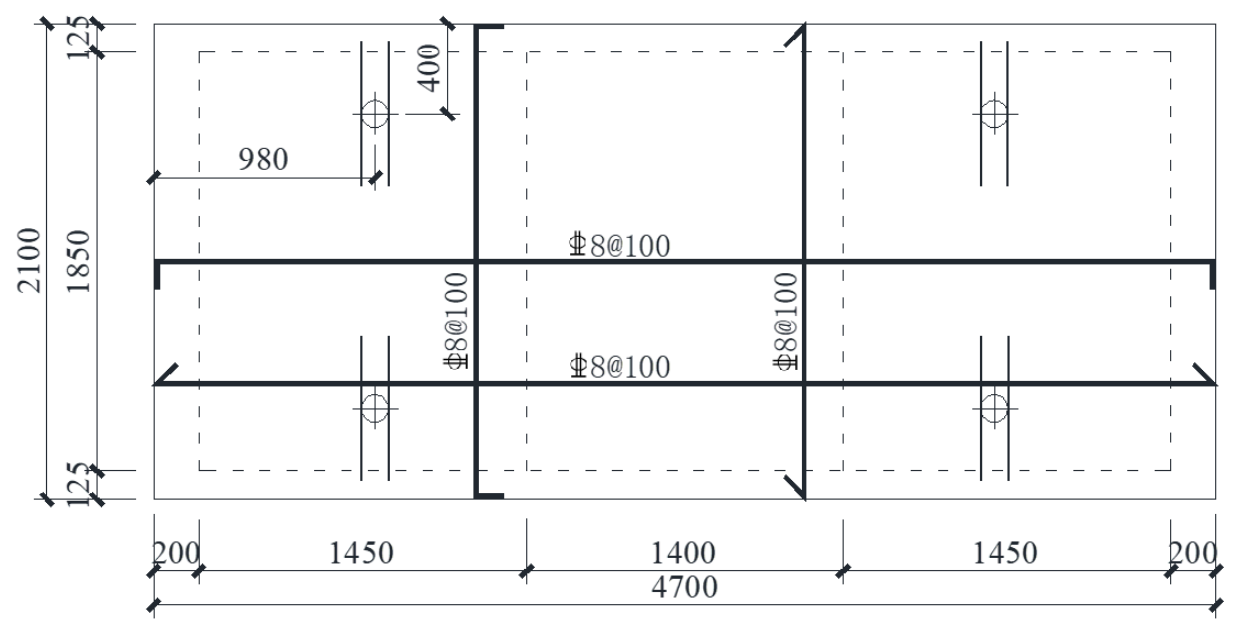

(b) Slab B3

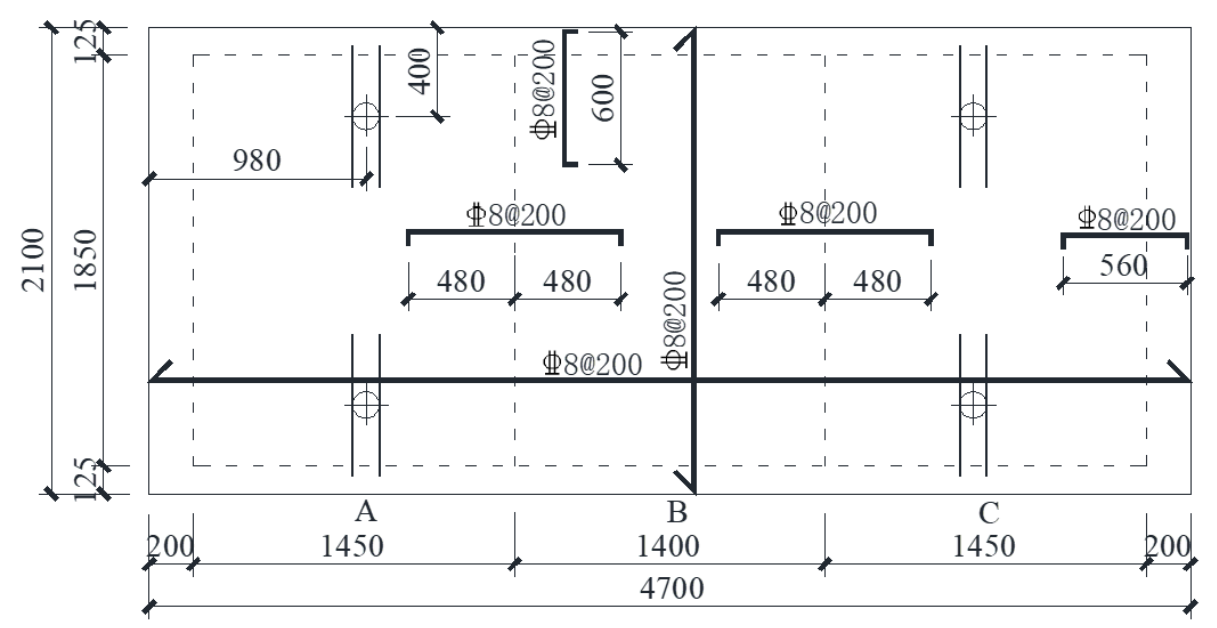

(c) Slab B4

Fig. 2 The details of reinforcing steel within four slabs (all dimensions in $\mathrm{mm}$ ) 


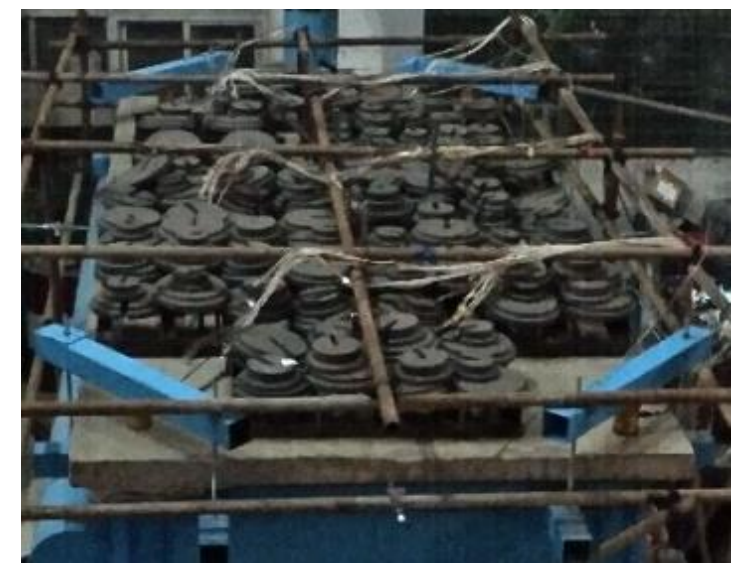

(a) Loading device

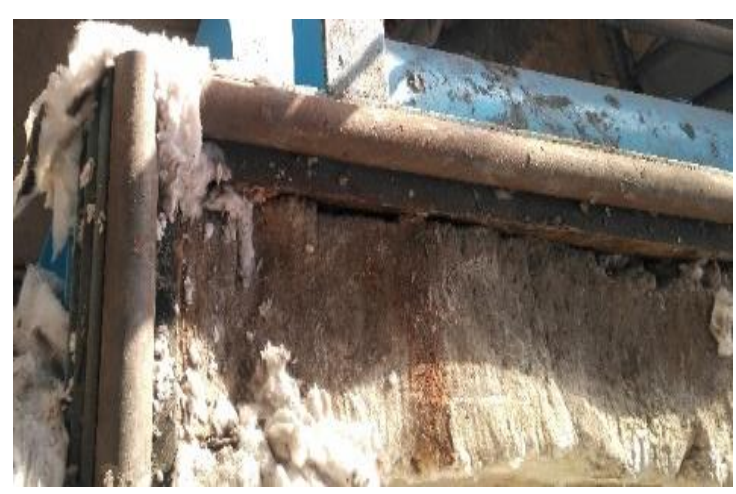

(b) Steel roller on the external furnace wall

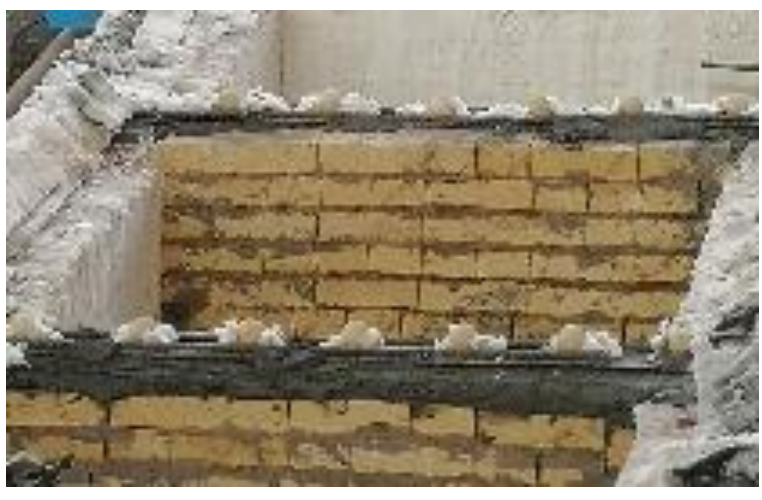

(c) Refractory pellet on the internal furnace wall 


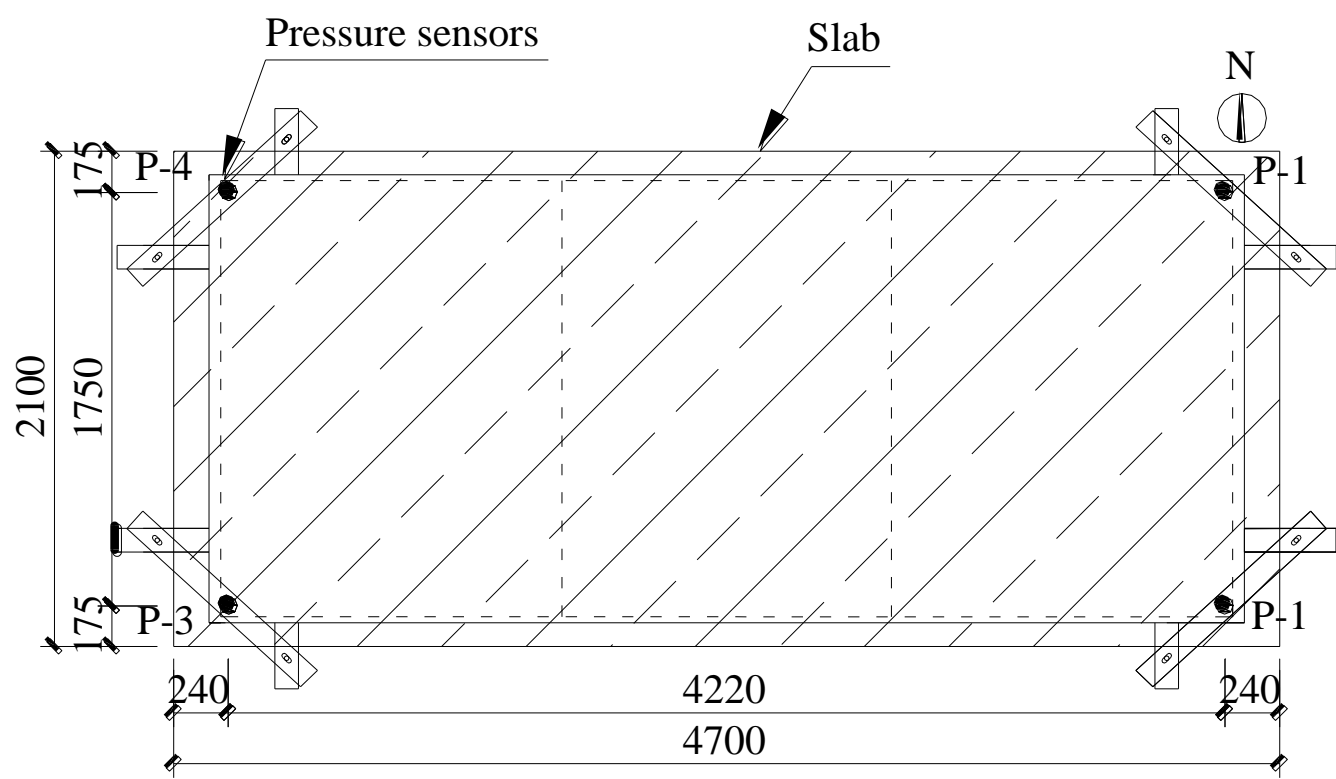

(d) Corners' restraint

Fig. 3 Loading device, supports on the furnace wall and corners' restraint (all dimensions in $\mathrm{mm}$ ) 


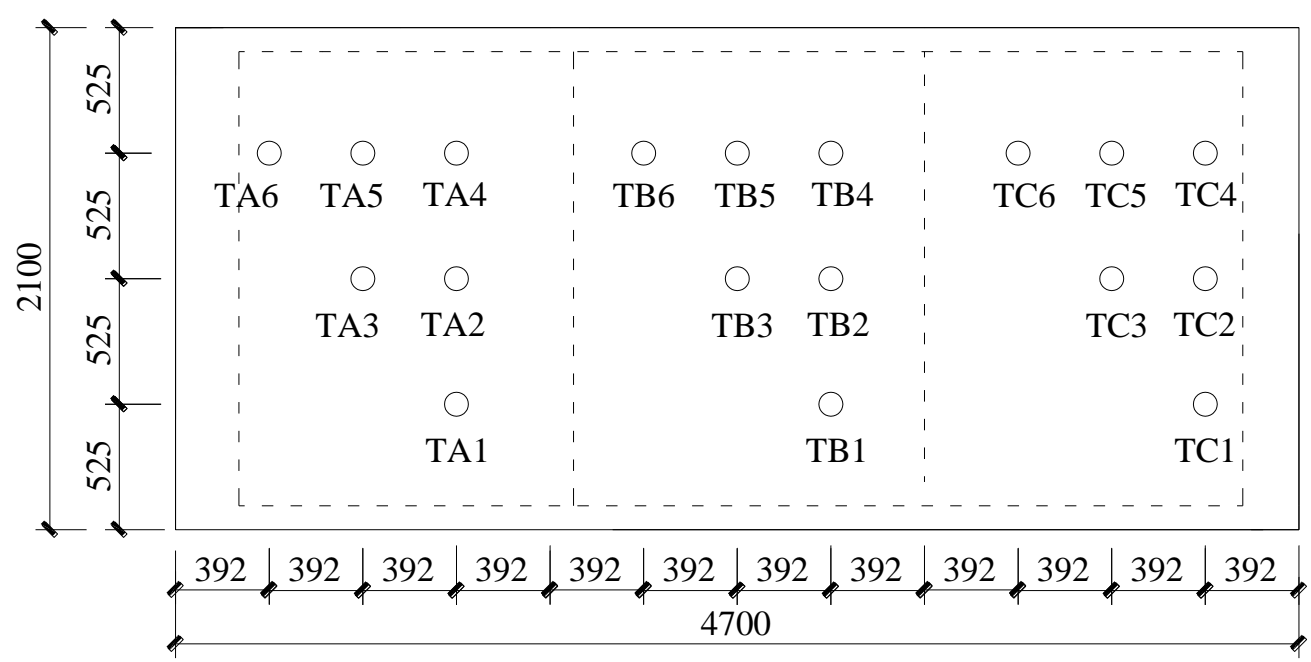

(a) Typical layout of thermocouples in the concrete slab

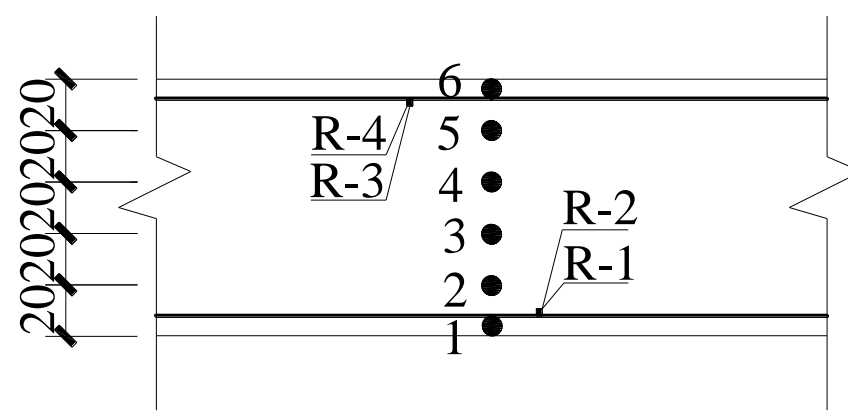

(b) Thermocouples across the full-depth of each slab

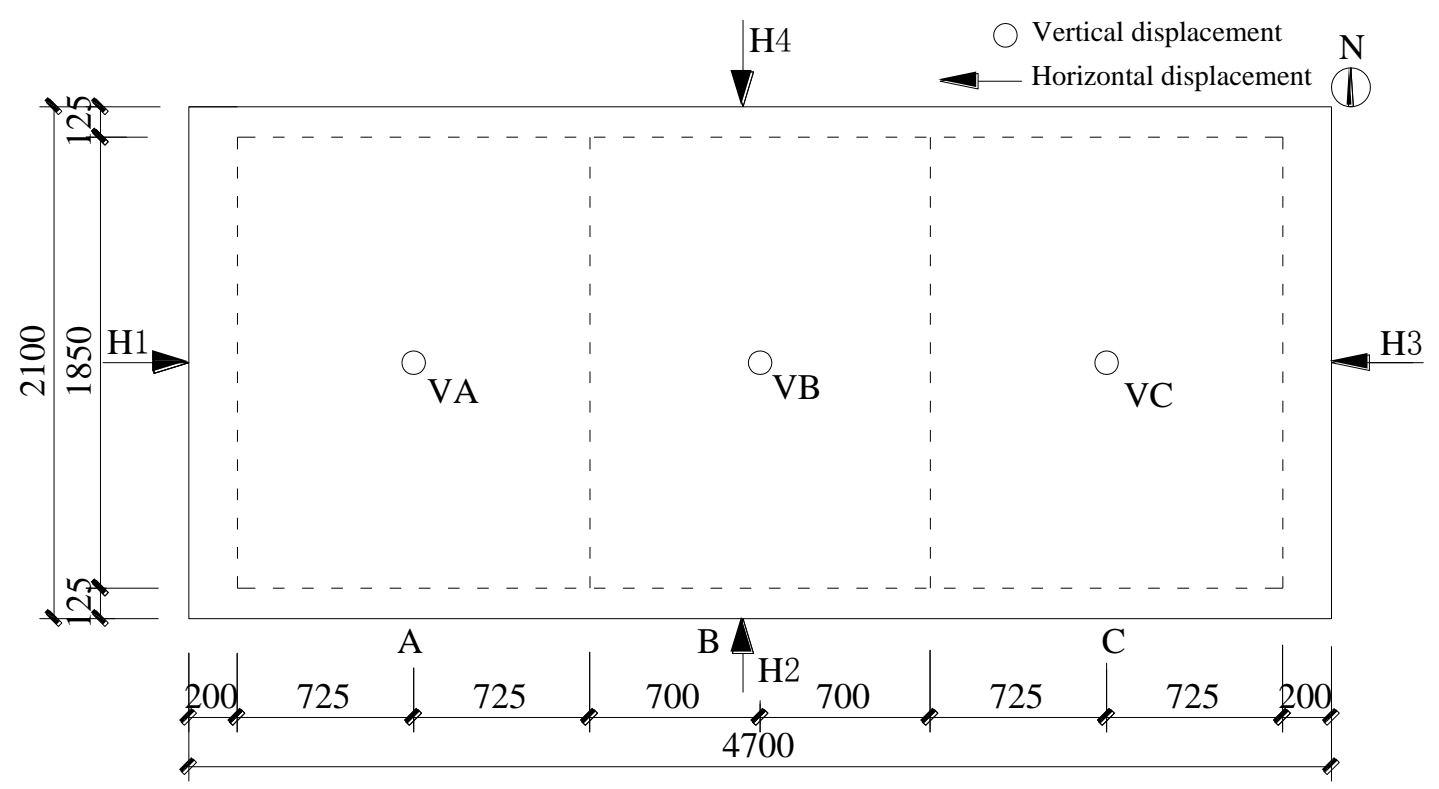

(c) Layout of the vertical and horizontal displacement transducers

Fig. 4 Thermocouple location and displacement transducers for each tested slab (all dimensions in $\mathrm{mm}$ ) 


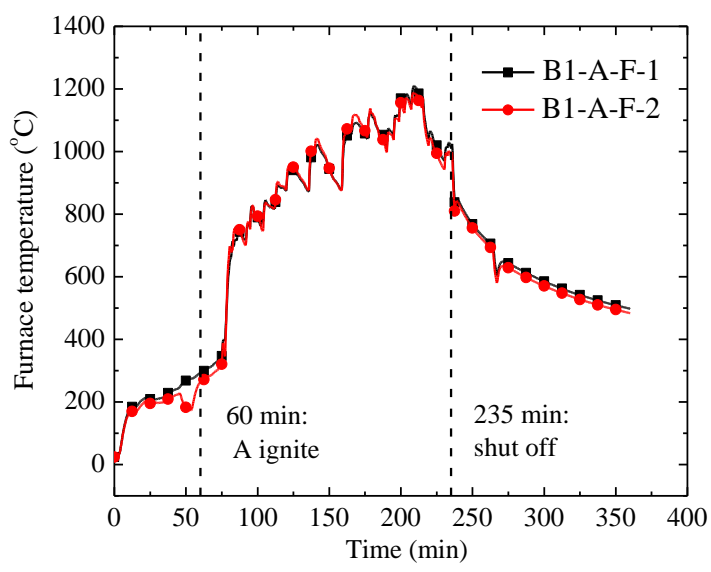

(a) Compartment $\mathrm{A}$

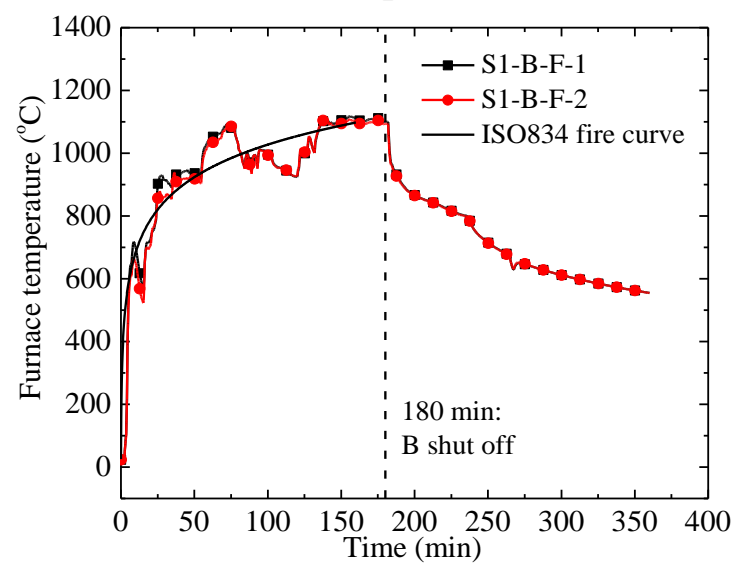

(b) Compartment B

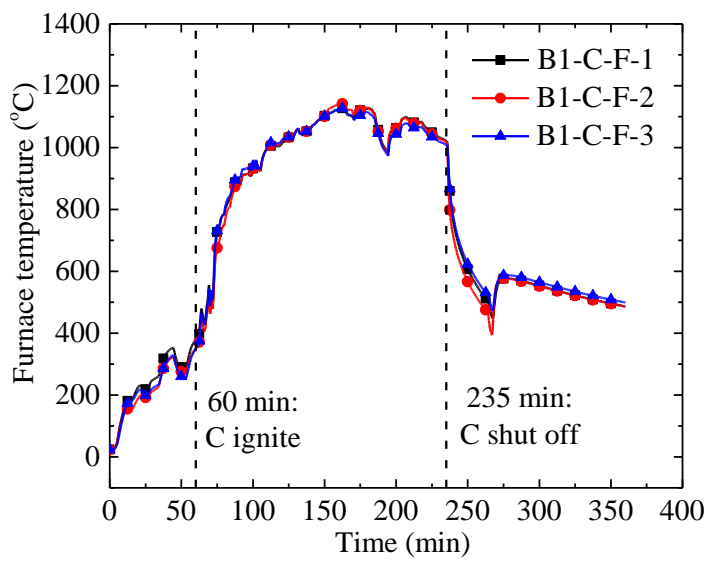

(c) Compartment $\mathrm{C}$

Fig. 5 Furnace temperature-time curves of Slab B1 


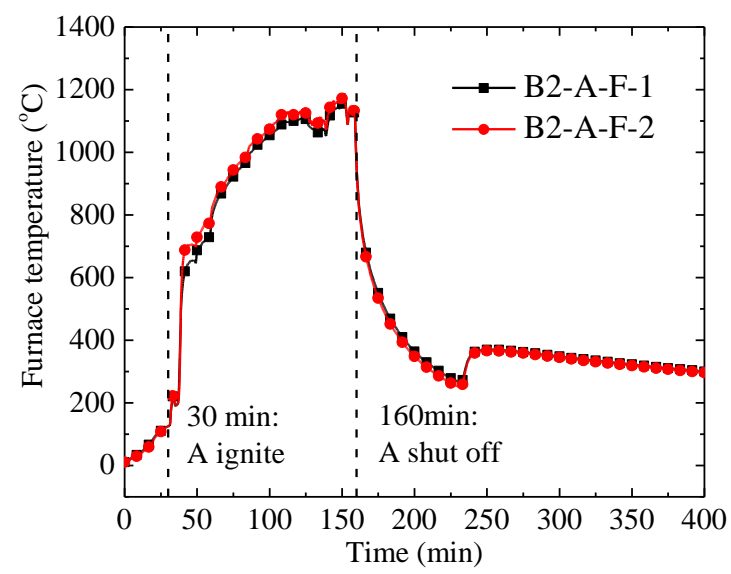

(a) Compartment $\mathrm{A}$

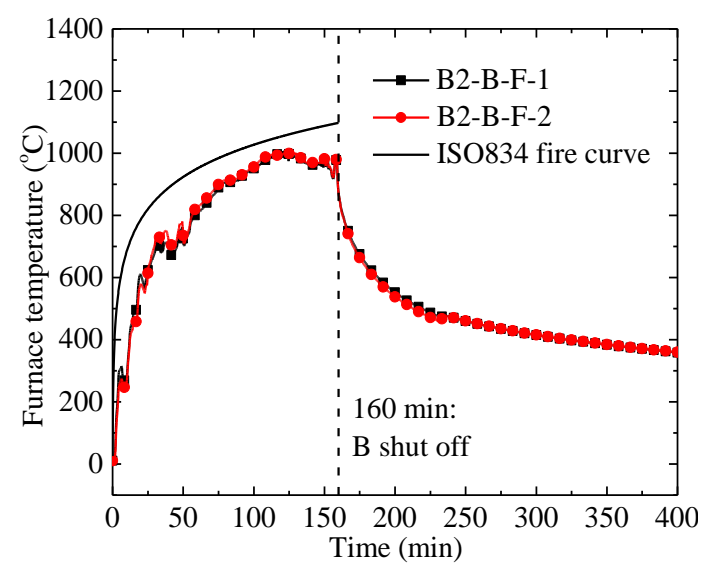

(b) Compartment $\mathrm{B}$

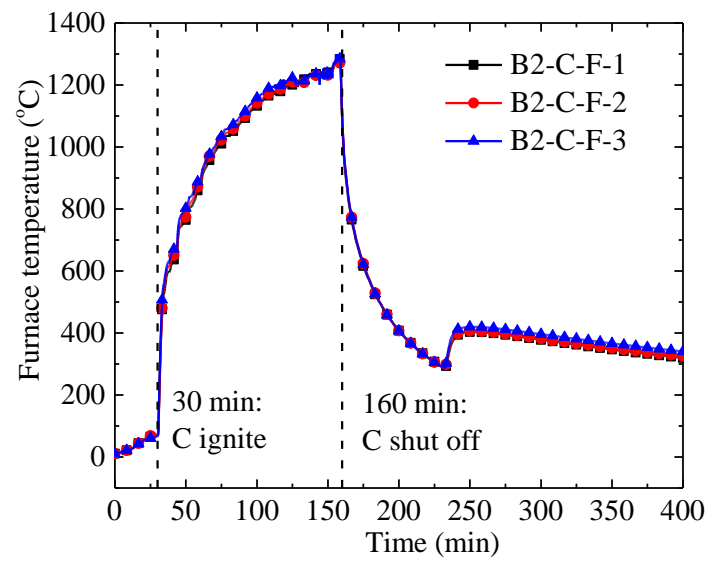

(c) Compartment $\mathrm{C}$

Fig. 6 Furnace temperature-time curves of Slab B2 


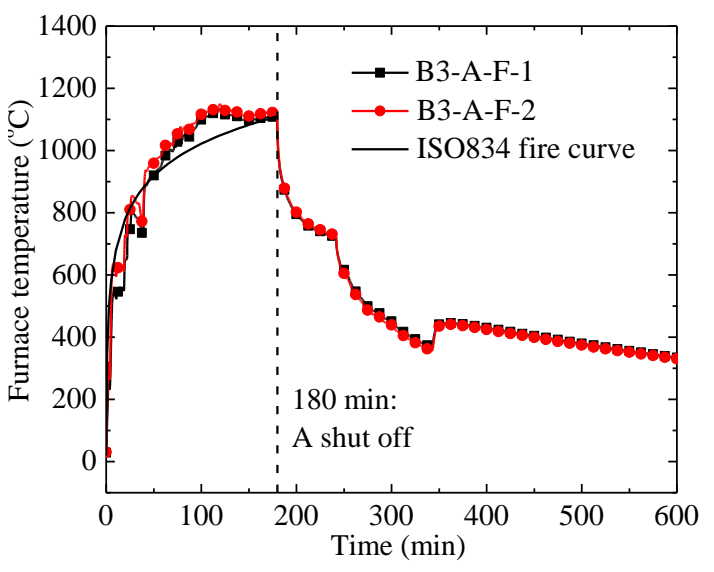

(a) Compartment $\mathrm{A}$

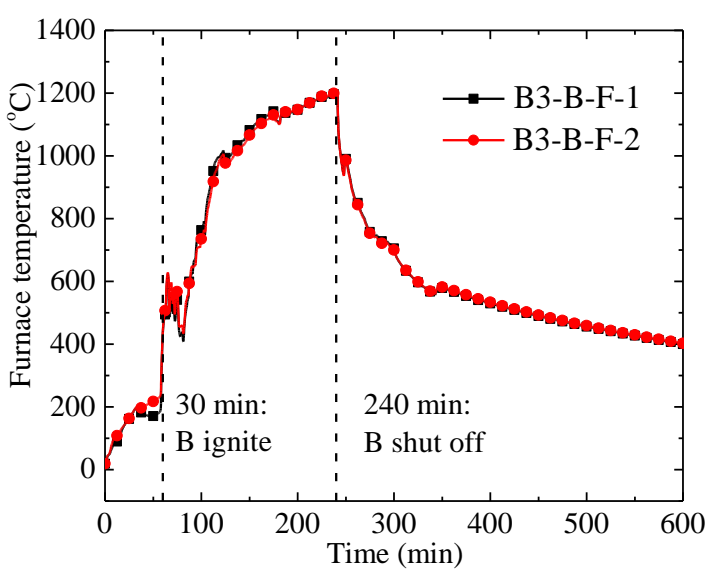

(b) Compartment B

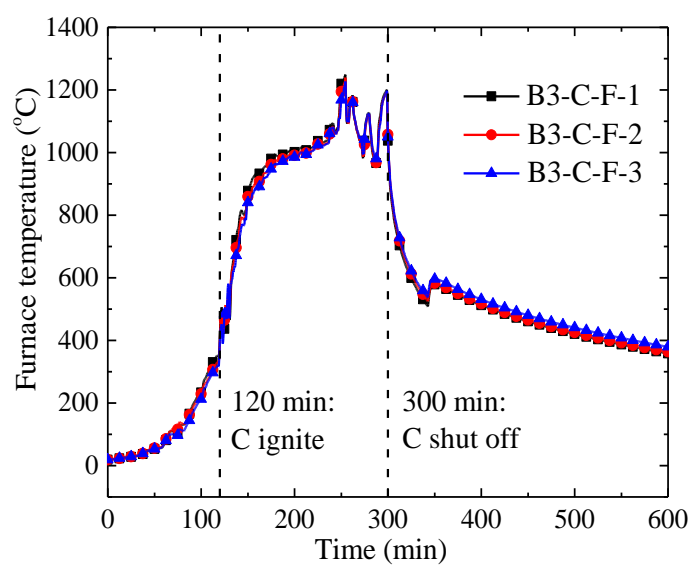

(c) Compartment $\mathrm{C}$

Fig. 7 Furnace temperature-time curves of Slab B3 


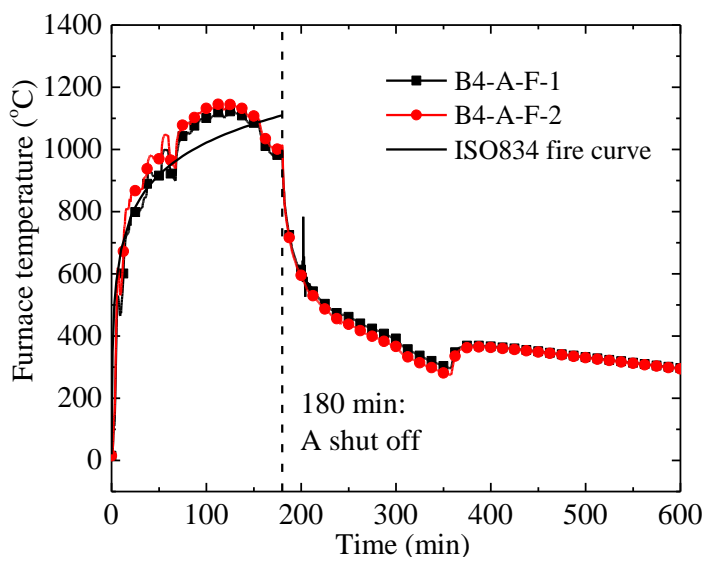

(a) Compartment $\mathrm{A}$

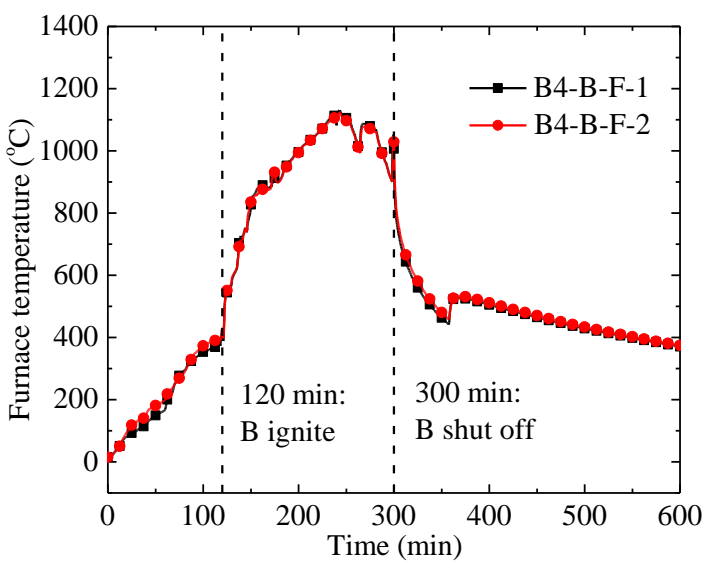

(b) Compartment B

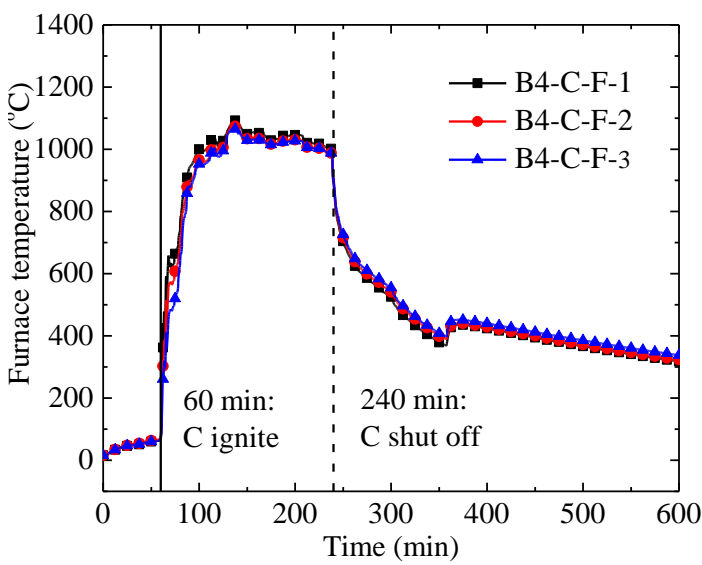

(c) Compartment $\mathrm{C}$

Fig. 8 Furnace temperature-time curves of Slab B4 


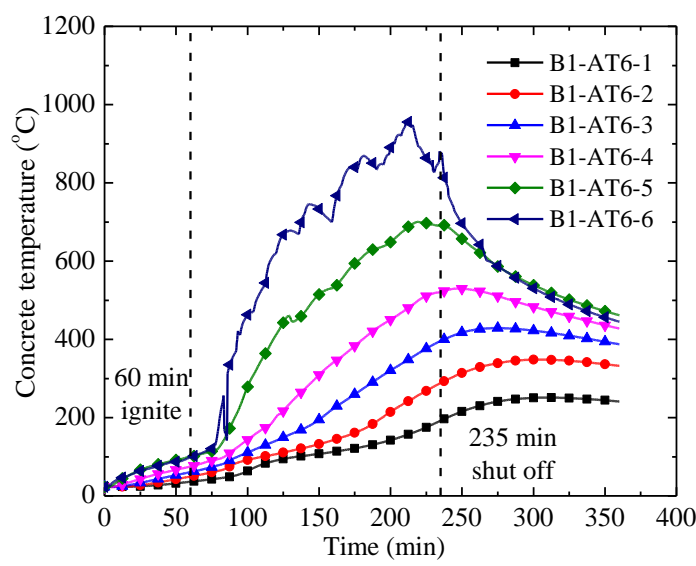

(a) Compartment $\mathrm{A}$

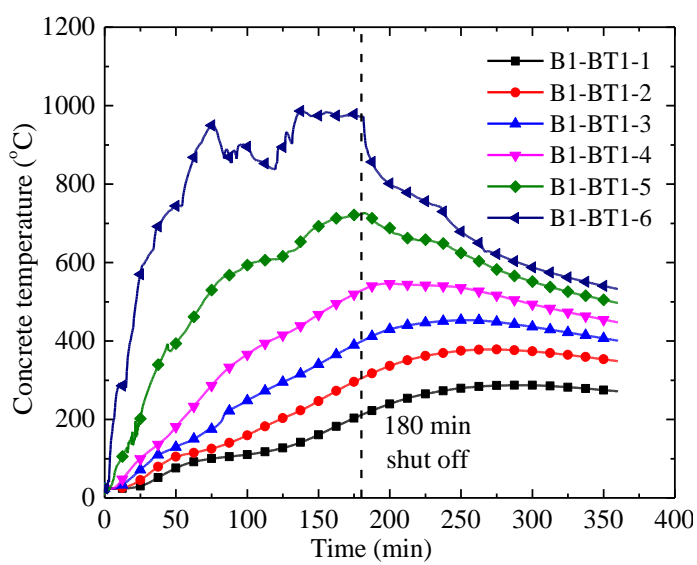

(b) Compartment $\mathrm{B}$

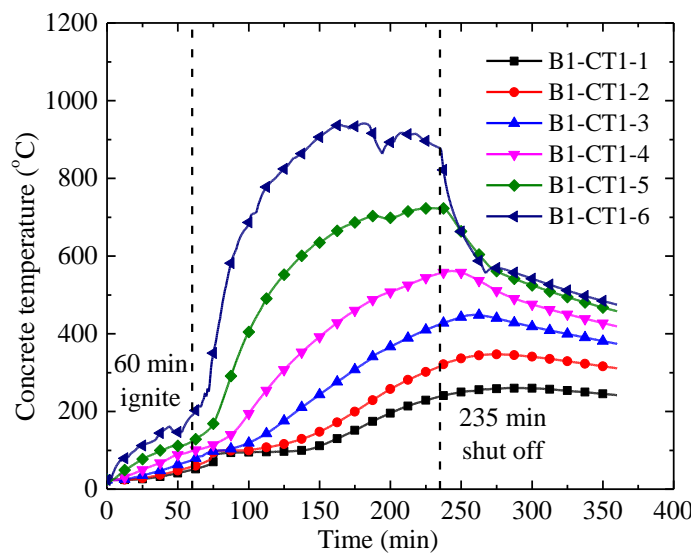

(c) Compartment $\mathrm{C}$

Fig. 9 Temperature distributions along the thickness of Slab B1 


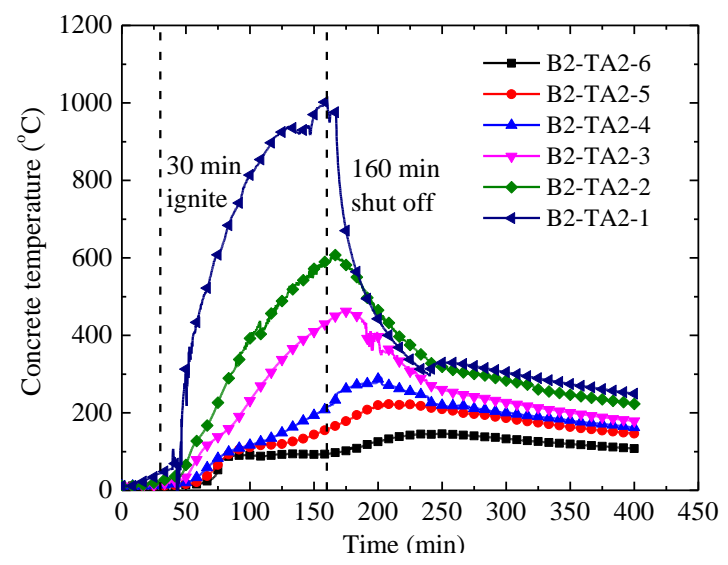

(a) Compartment $\mathrm{A}$

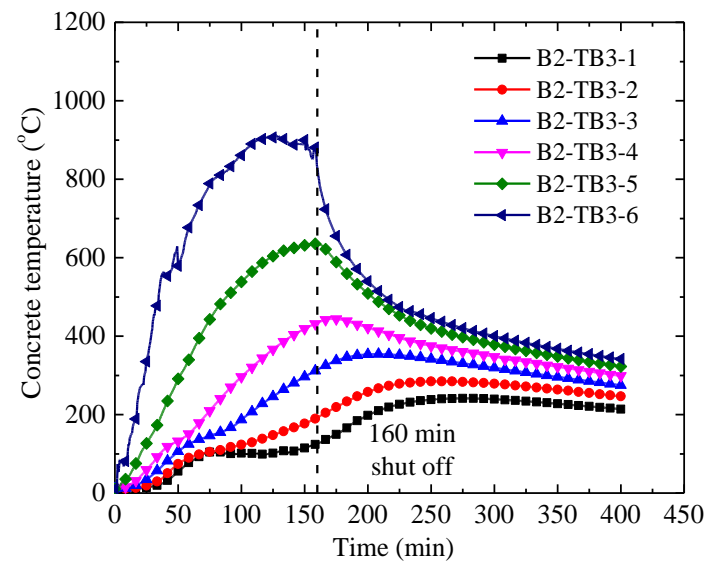

(b) Compartment B

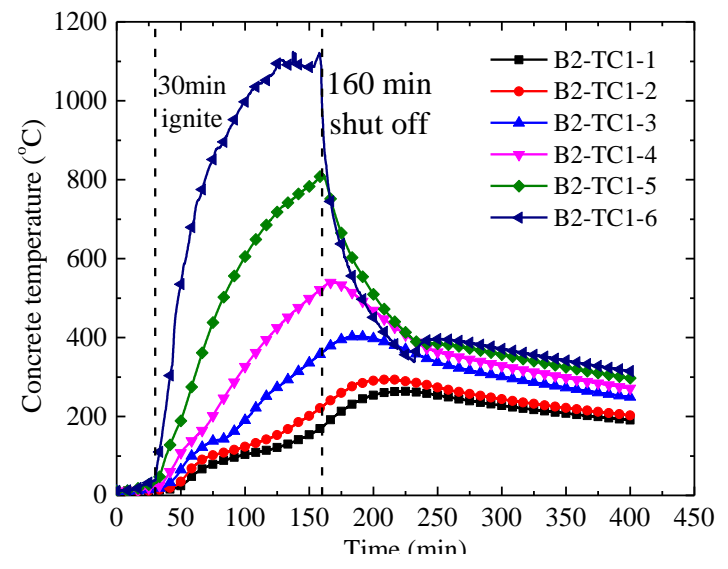

(c) Compartment $\mathrm{C}$

Fig. 10 Temperature distributions along the thickness of Slab B2 


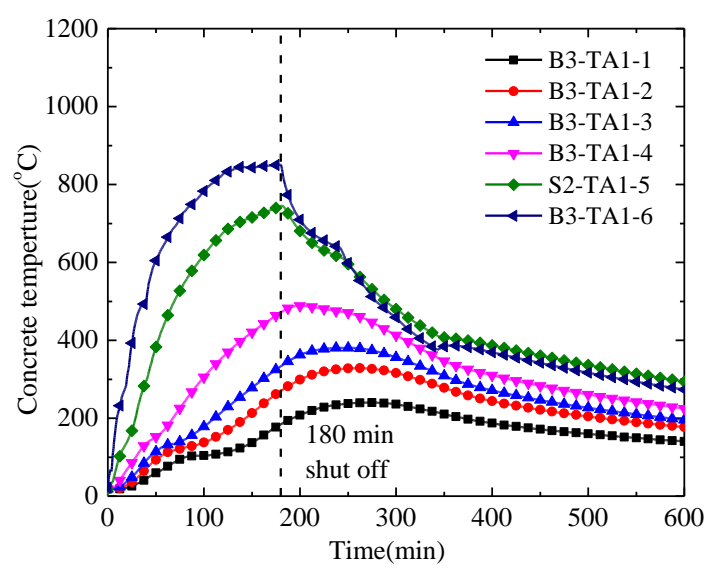

(a) Compartment $\mathrm{A}$

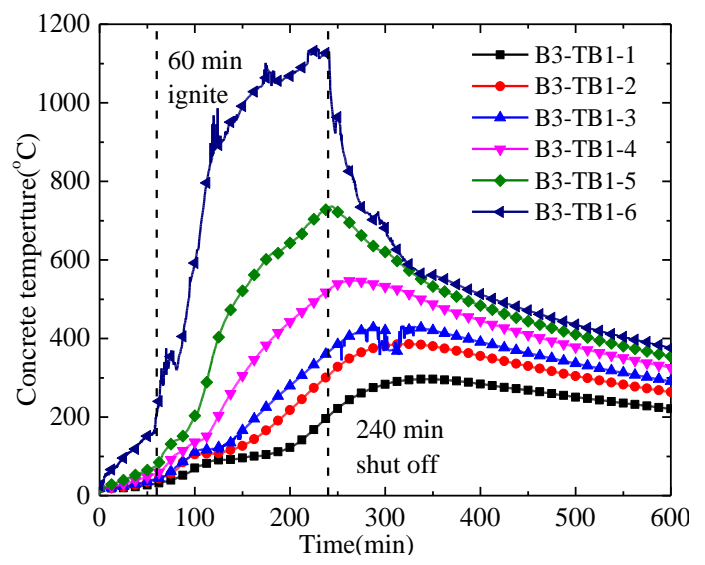

(b) Compartment $\mathrm{B}$

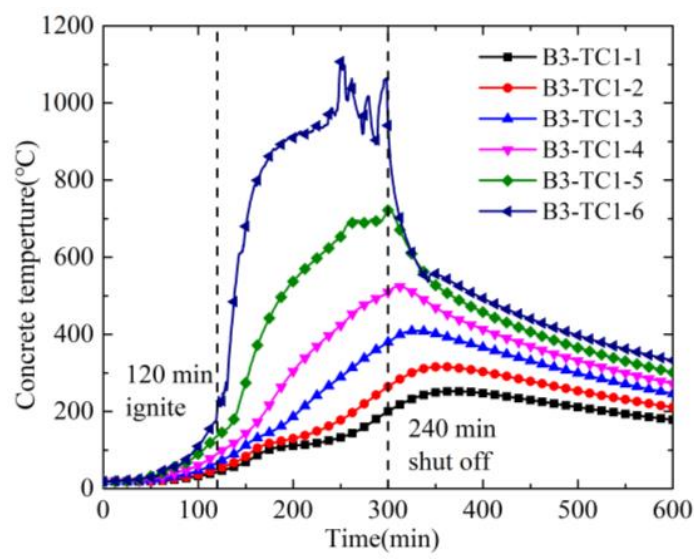

(c) Compartment $\mathrm{C}$

Fig. 11 Temperature distributions along the thickness of Slab B3 


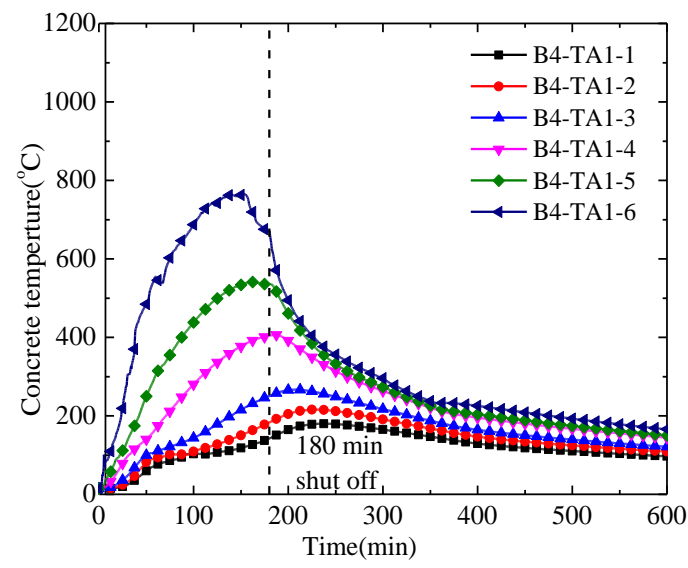

(a) Compartment $\mathrm{A}$

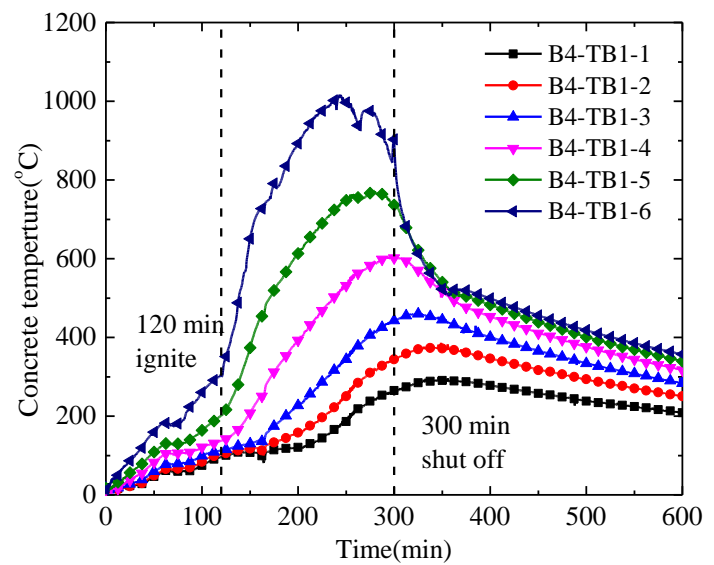

(b) Compartment B

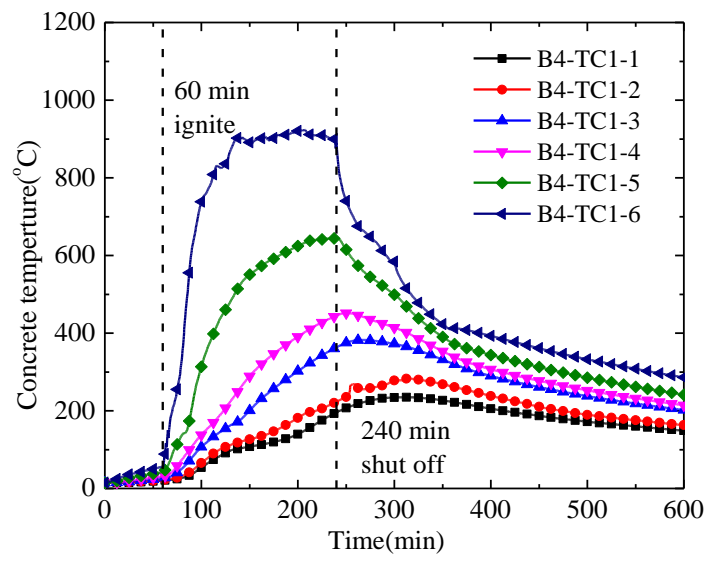

(c) Compartment $\mathrm{C}$

Fig. 12 Temperature distributions along the thickness of Slab B4 


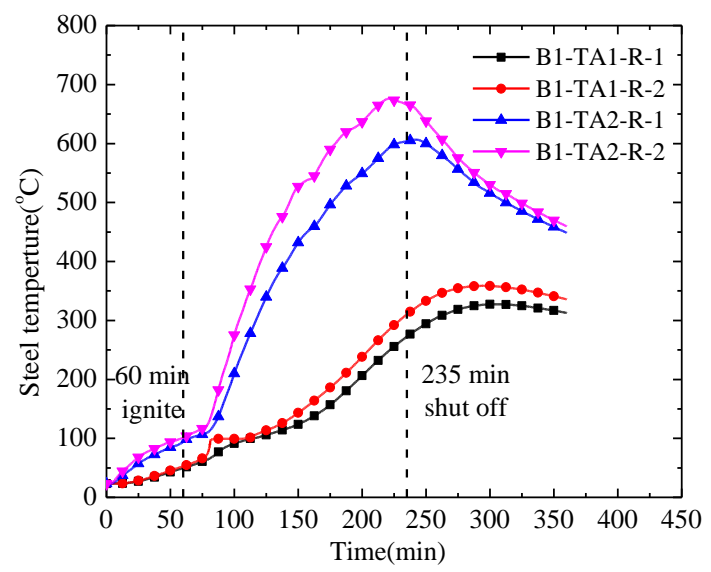

(a) Compartment $\mathrm{A}$

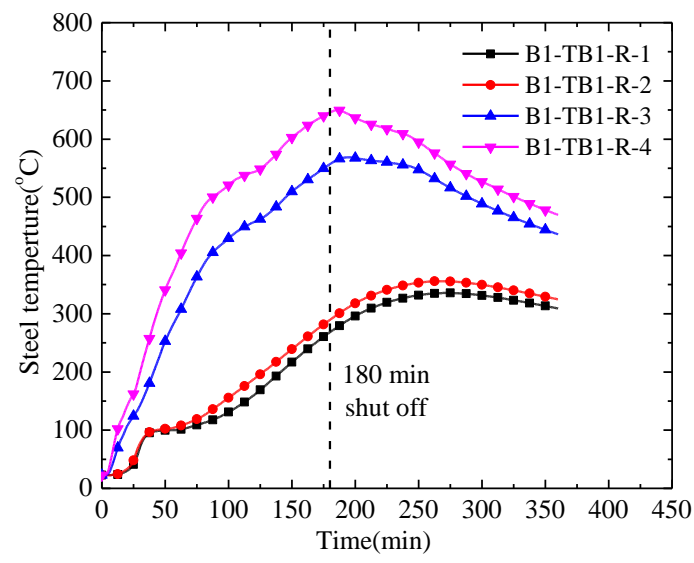

(b) Compartment B

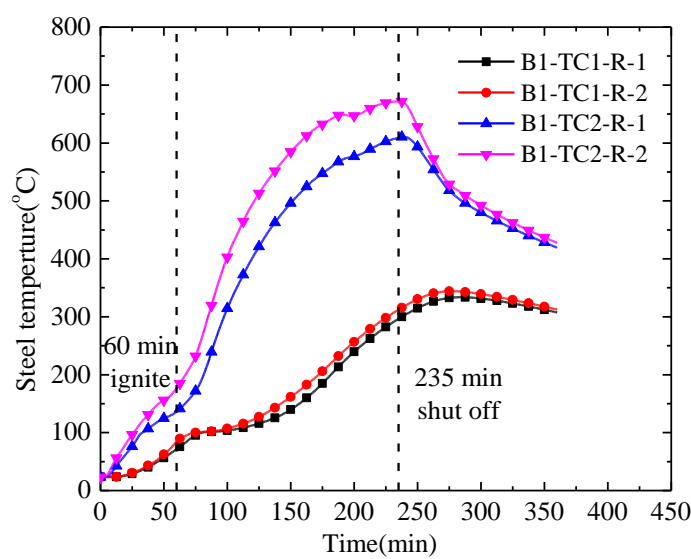

(c) Compartment $\mathrm{C}$

Fig. 13 Temperatures of the reinforcing steels of Slab B1 


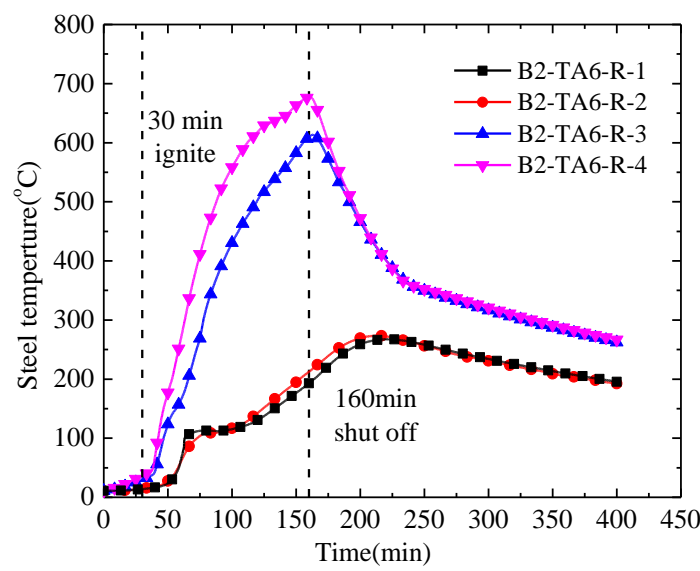

(a) Compartment $\mathrm{A}$

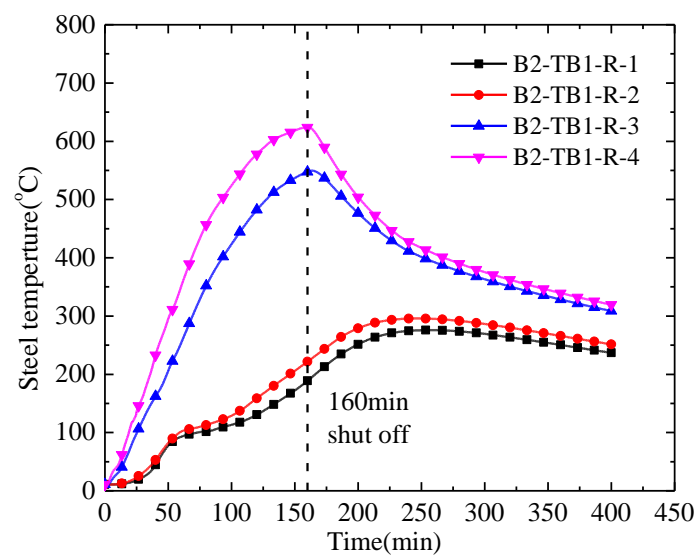

(b) Compartment B

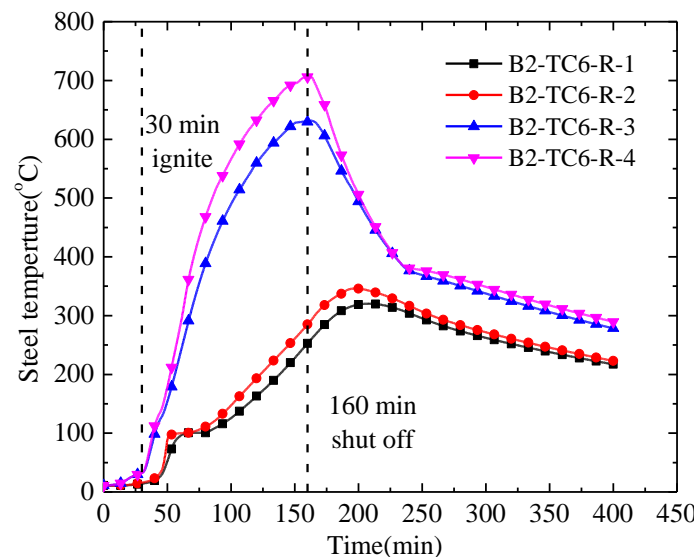

(c) Compartment $\mathrm{C}$

Fig. 14 Temperatures of the reinforcing steels of Slab B2 


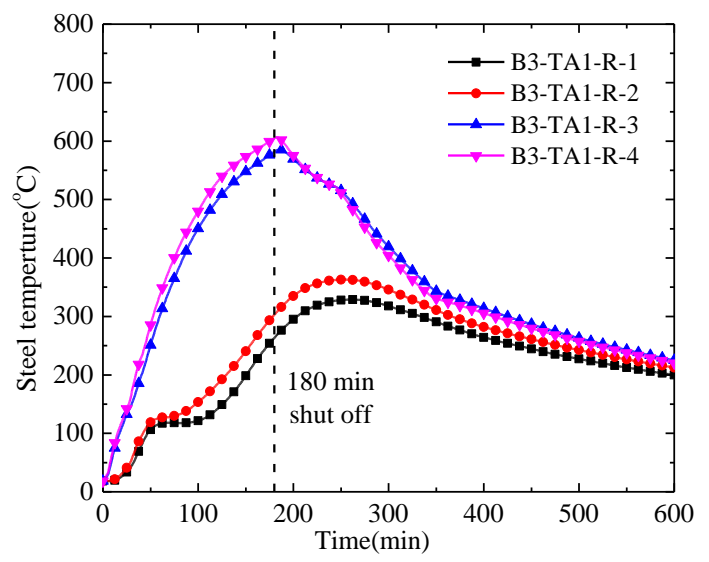

(a) Compartment $\mathrm{A}$

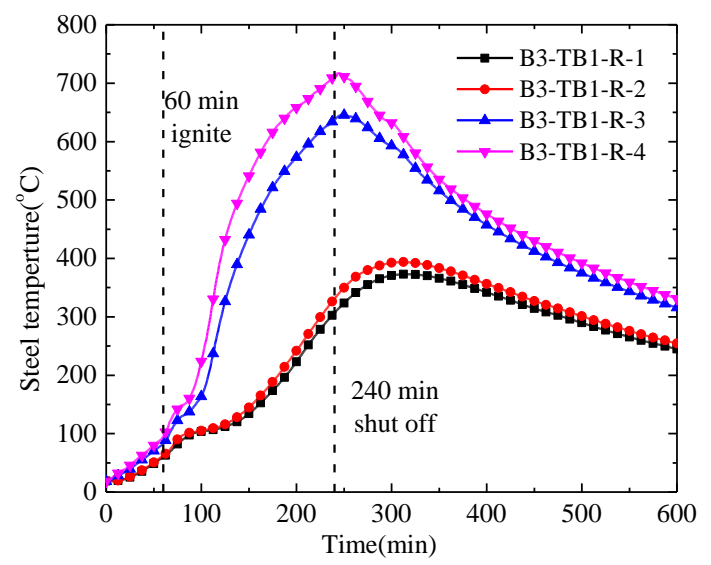

(b) Compartment B

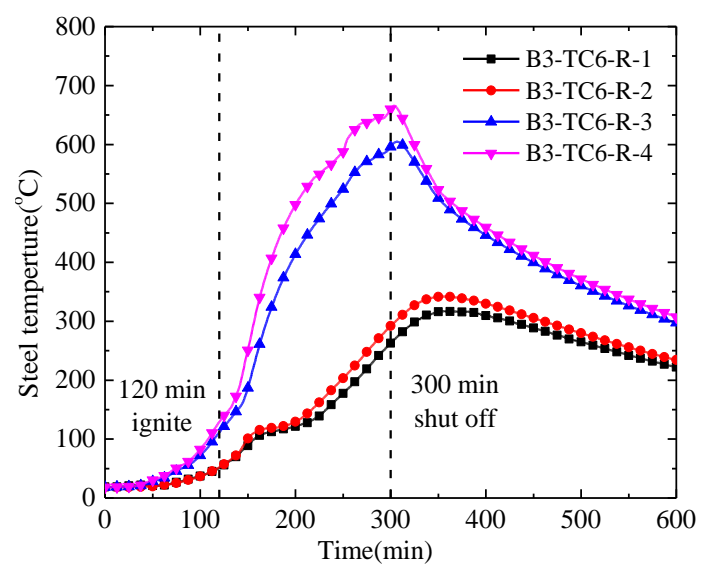

(c) Compartment $\mathrm{C}$

Fig. 15 Temperatures of the reinforcing steels of Slab B3 


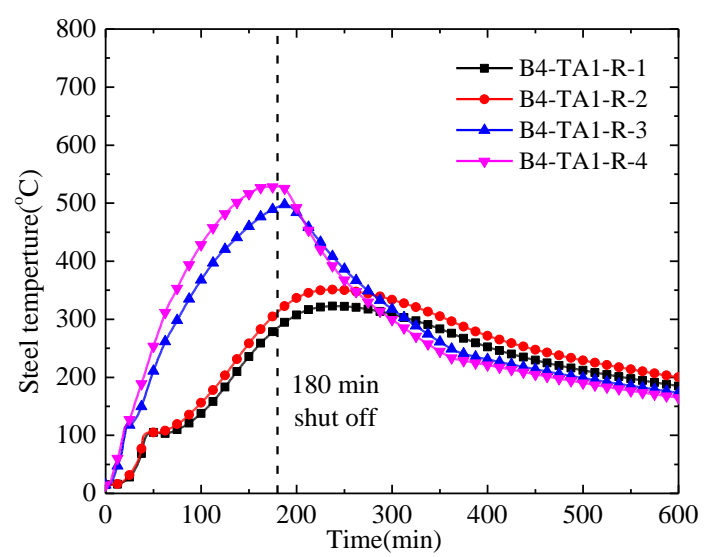

(a) Compartment $\mathrm{A}$

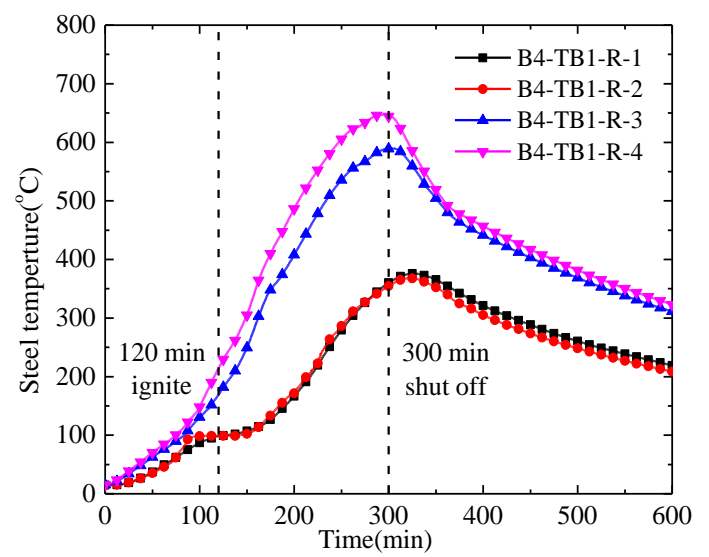

(b) Compartment $\mathrm{B}$

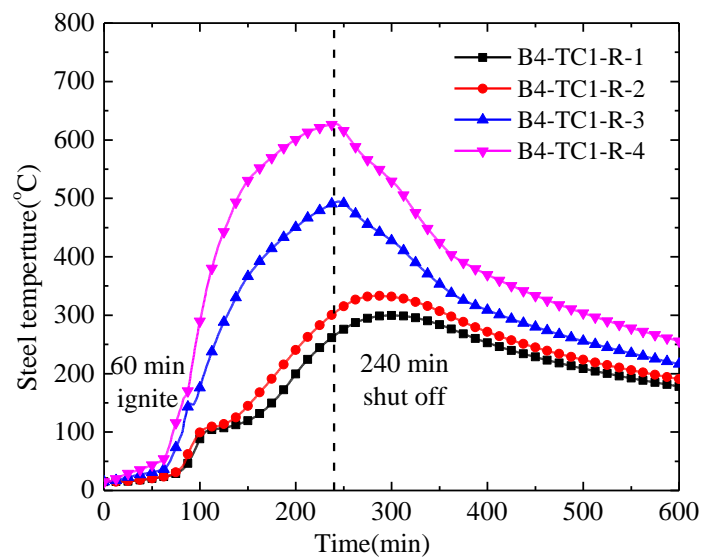

(c) Compartment $\mathrm{C}$

Fig. 16 Temperatures of the reinforcing steels of Slab B4 


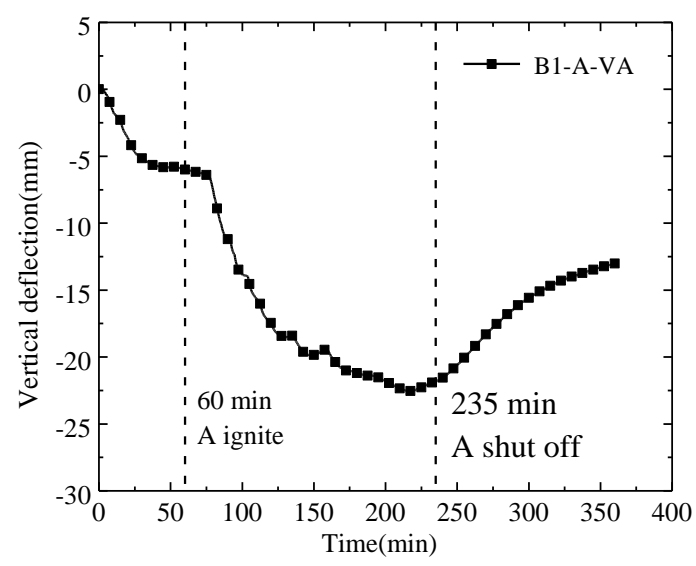

(a) Compartment $\mathrm{A}$

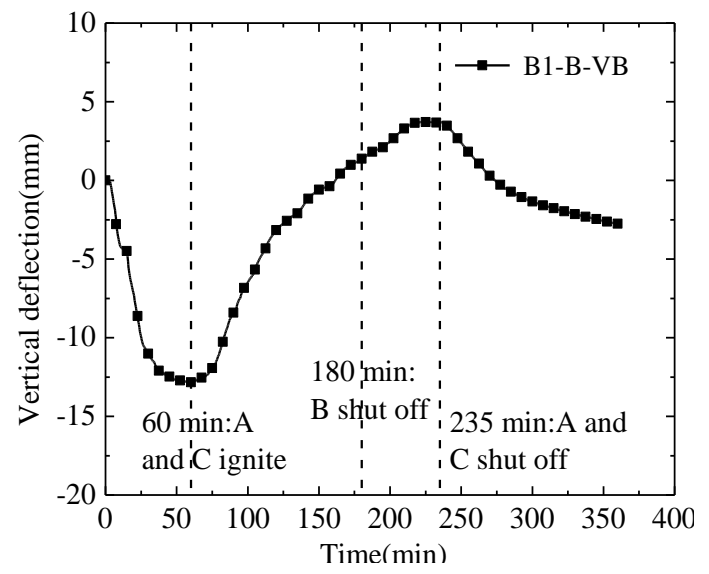

(b) Compartment B

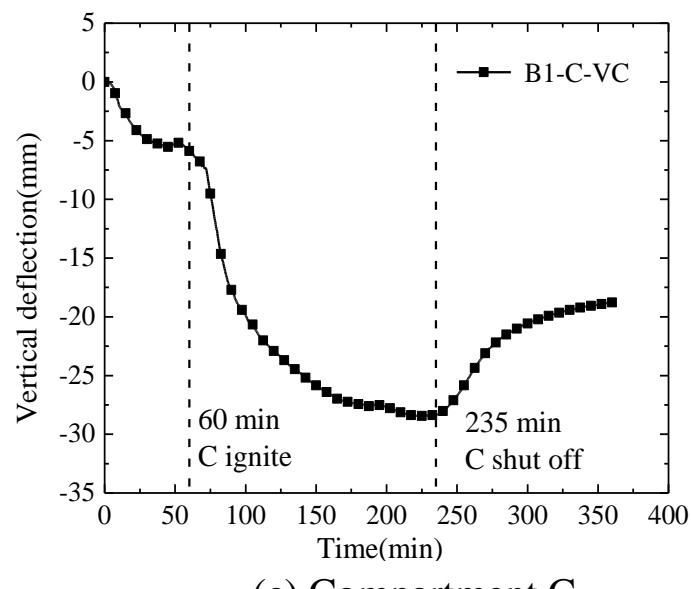

(c) Compartment $\mathrm{C}$

Fig. 17 Vertical deflections-time curves of Slab B1 


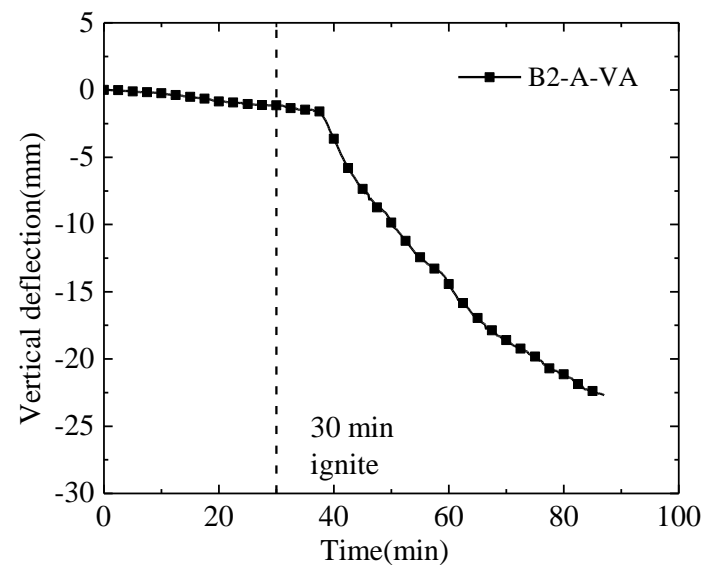

(a) Compartment $\mathrm{A}$

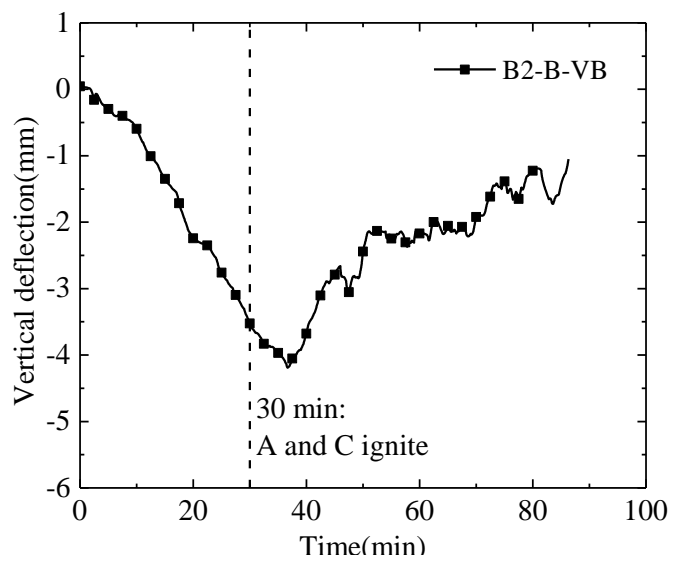

(b) Compartment B

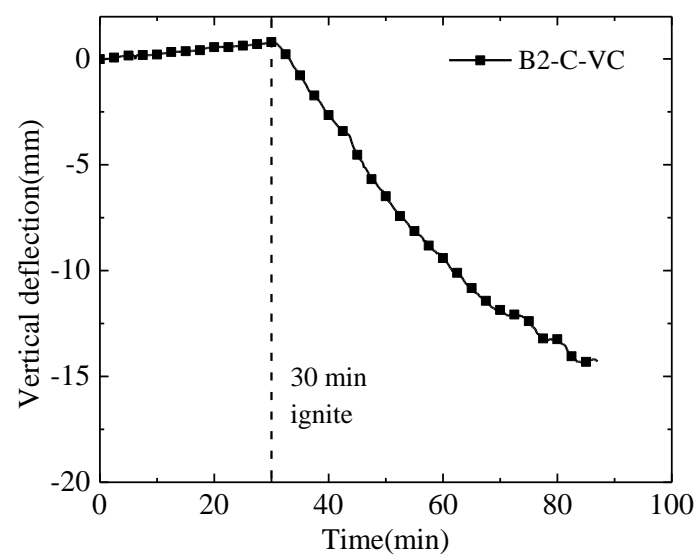

(c) Compartment $\mathrm{C}$

Fig. 18 Vertical deflections-time curves of Slab B2 


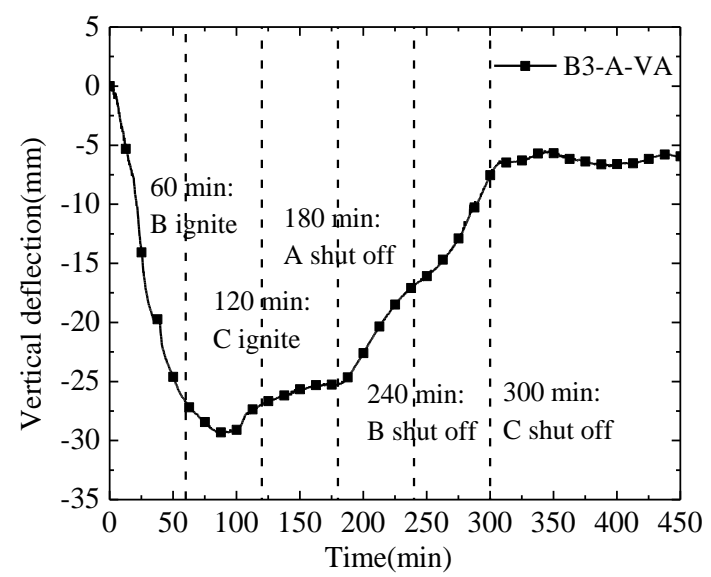

(a) Compartment $\mathrm{A}$

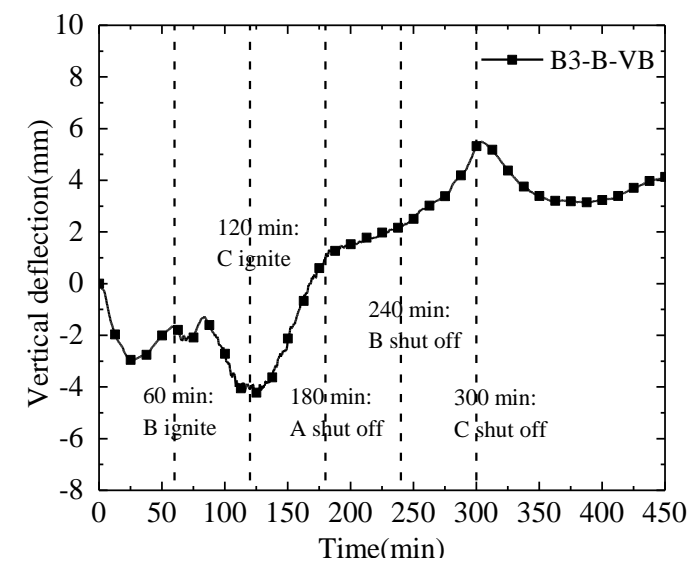

(b) Compartment B

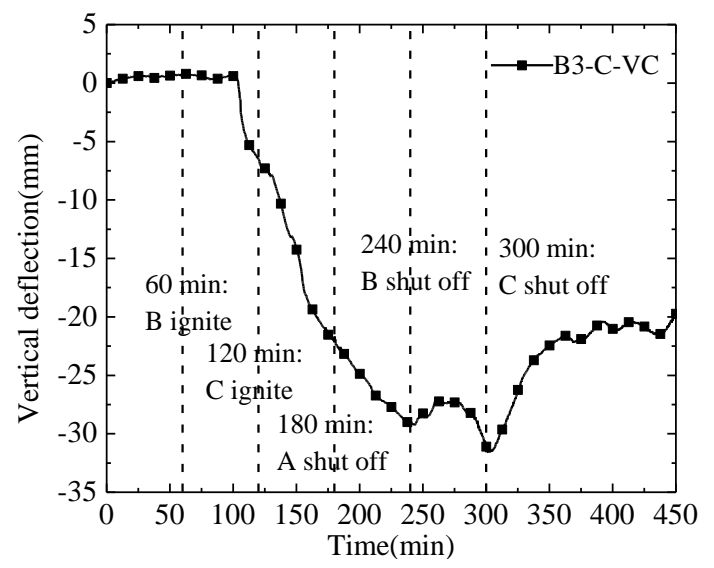

(c) Compartment $\mathrm{C}$

Fig. 19 Vertical deflections-time curves of Slab B3 


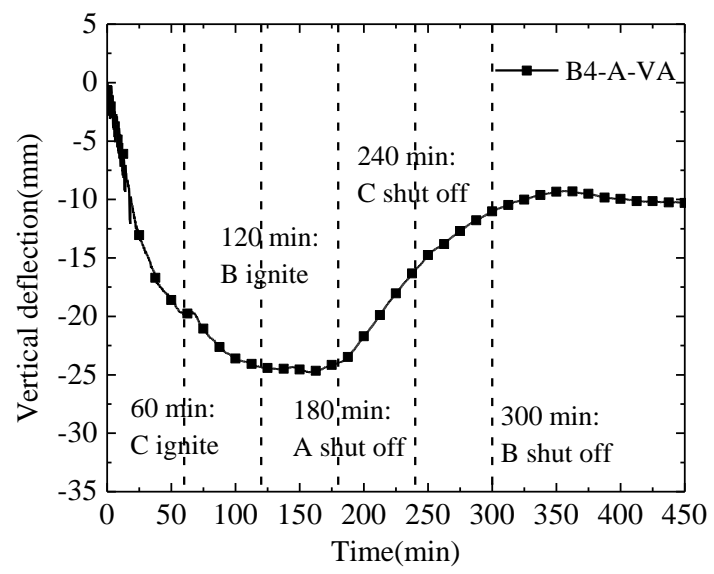

(a) Compartment $\mathrm{A}$

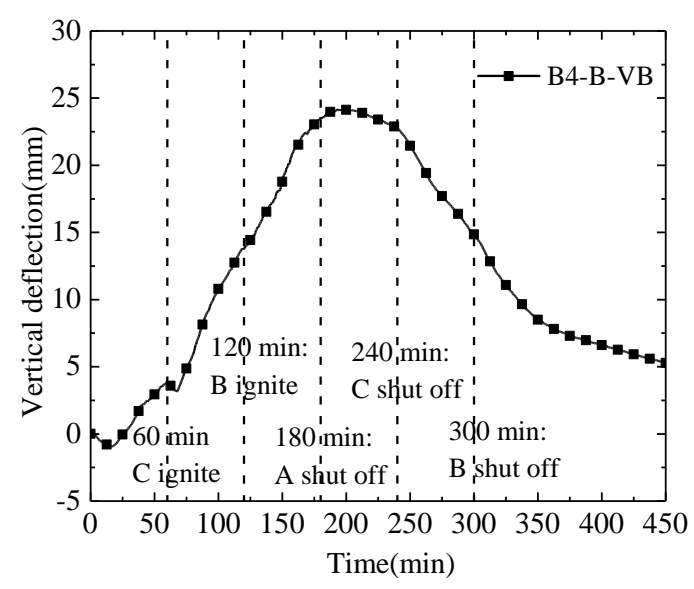

(b) Compartment B

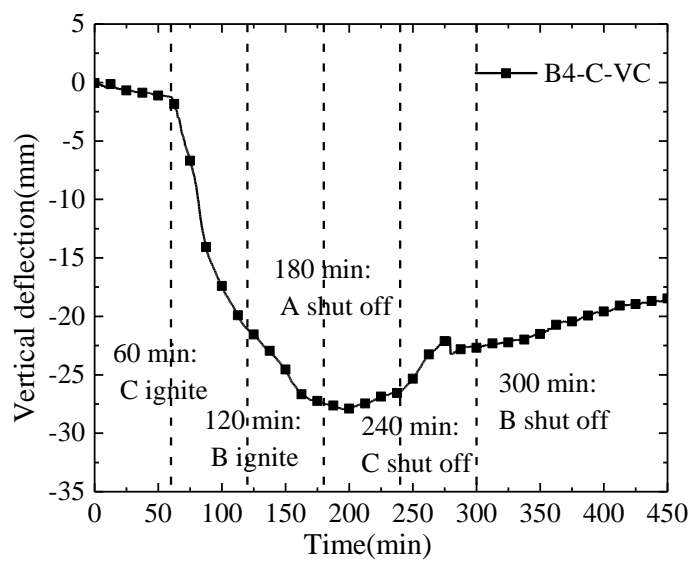

(c) Compartment $\mathrm{C}$

Fig. 20 Vertical deflections-time curves of Slab B4 


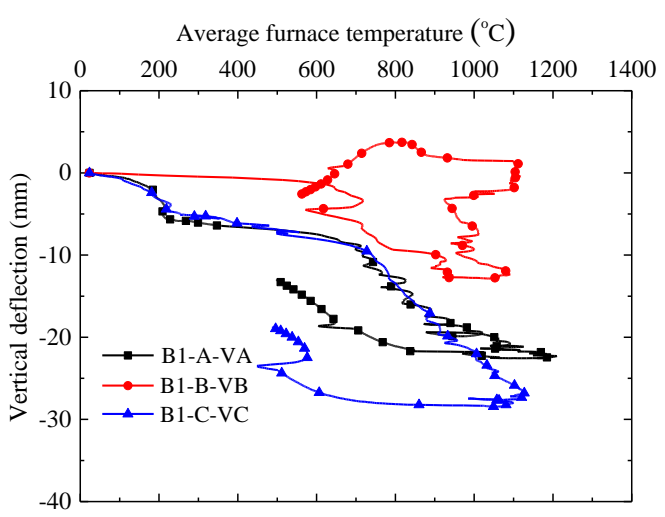

(a) Slab B1

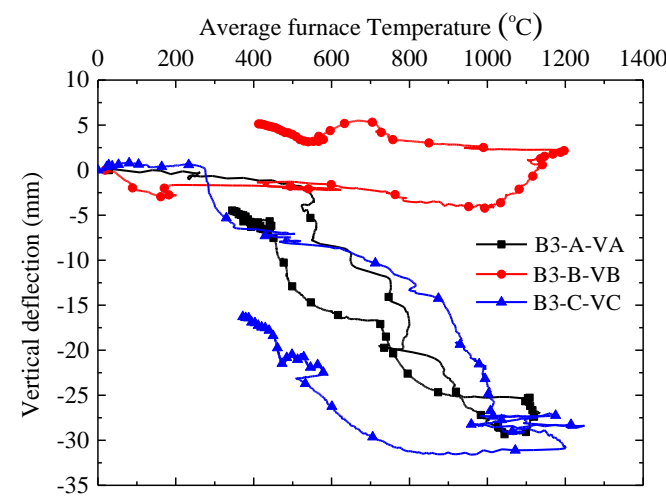

(c) Slab B3

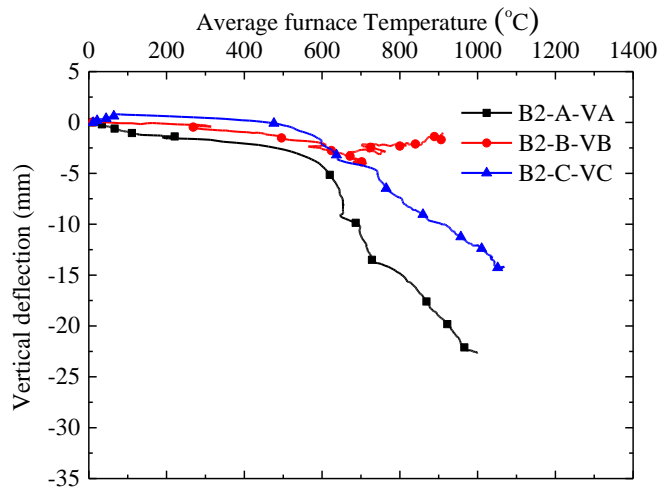

(b) Slab B2

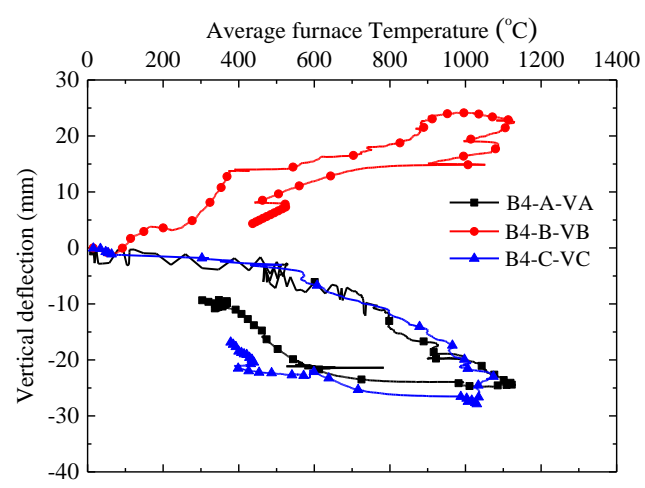

(d) Slab B4

Fig. 21 Vertical deflections-average furnace temperature curves of four slabs 


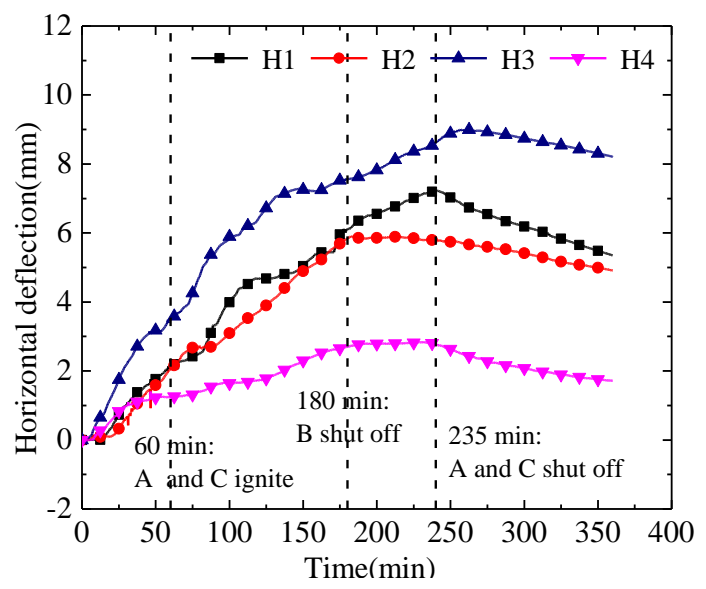

(a) Slab B1

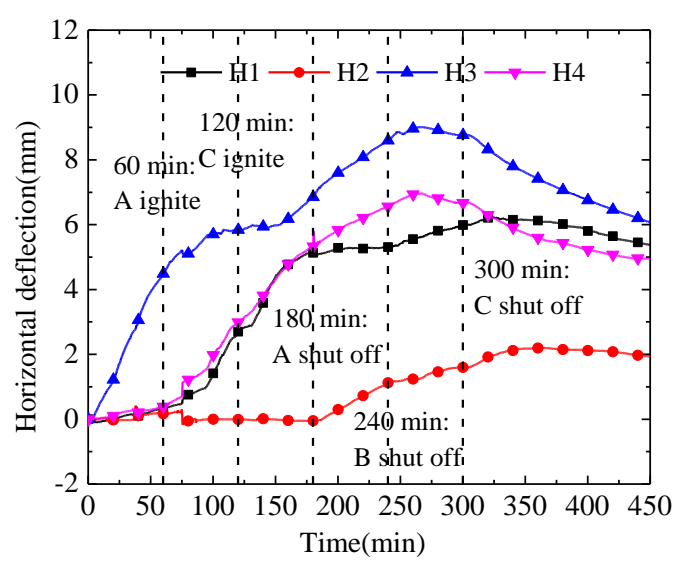

(c) Slab B3

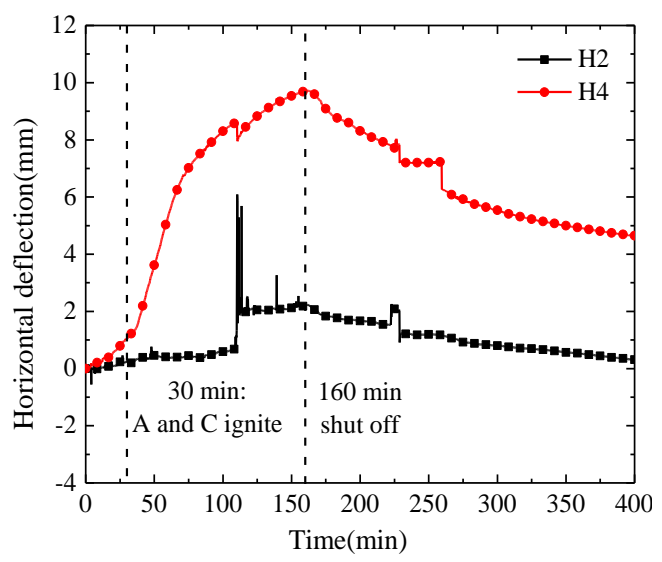

(b) Slab B2

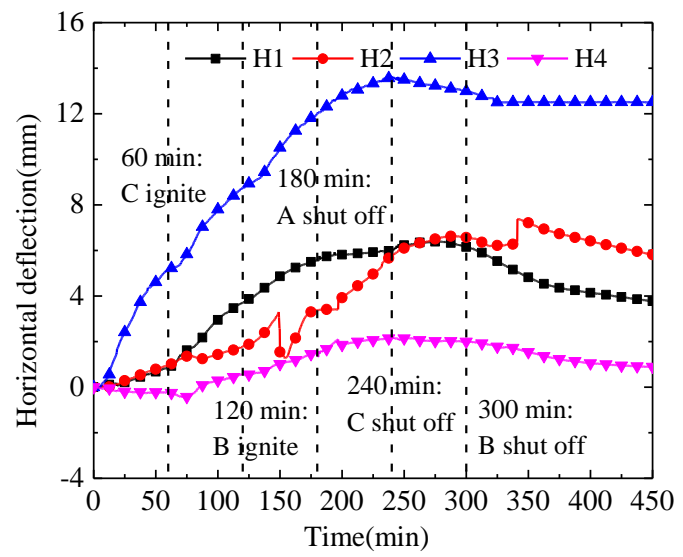

(d) Slab B4

Fig. 22 Horizontal deflections-time curves of four slabs: (a) Slab B1, (b) Slab B2, (c) Slab B3 and (d) Slab B4 


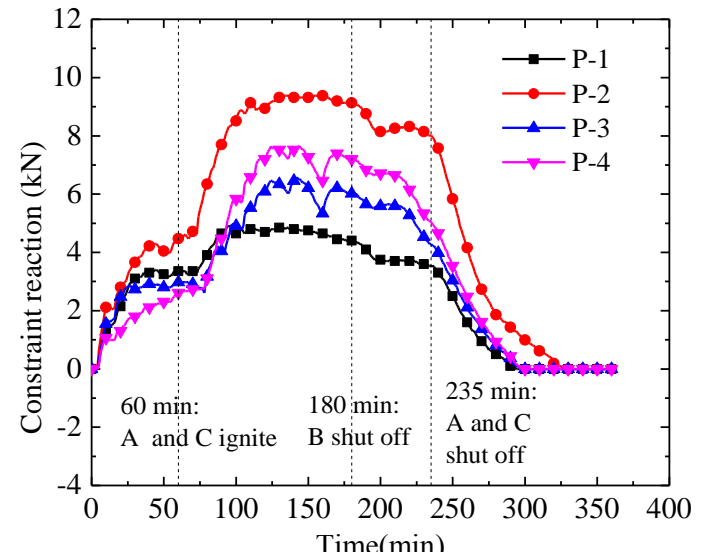

(a) Slab B1

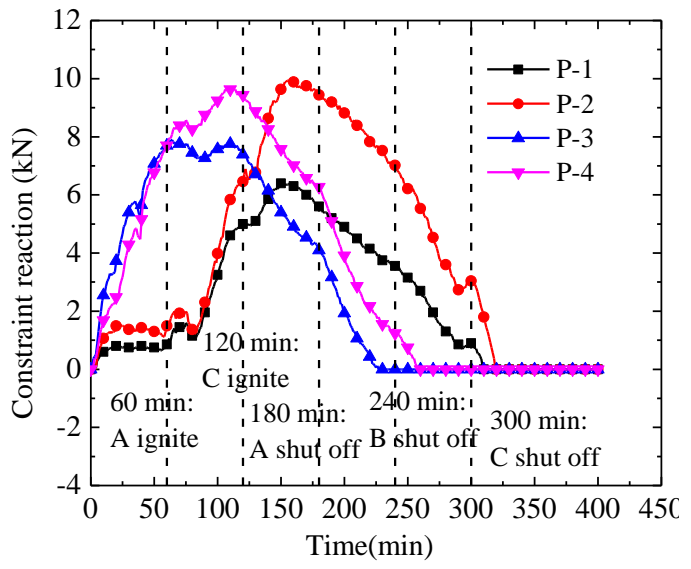

(c) Slab B3

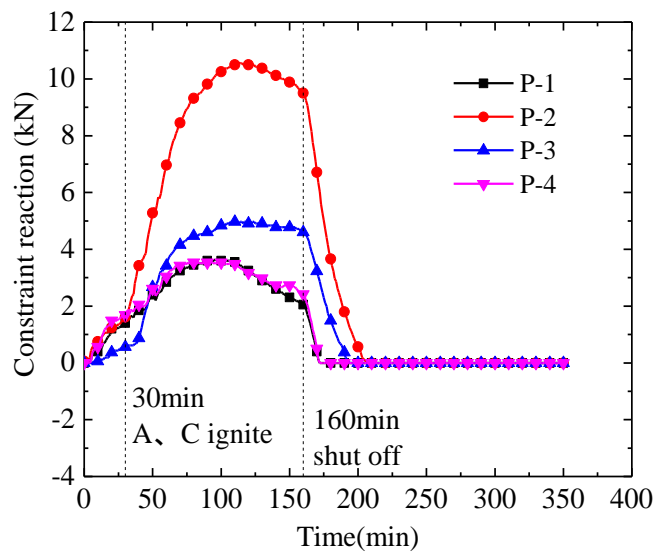

(b) Slab B2

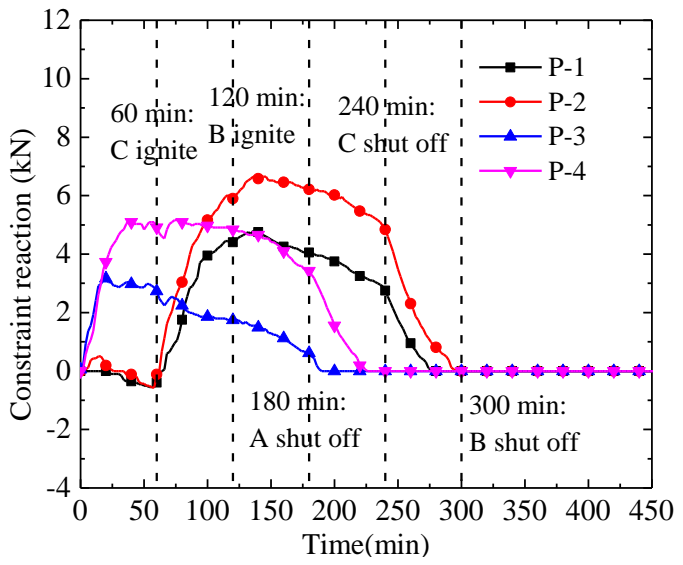

(d) Slab B4

Fig. 23 Restraining forces at the corners of four slabs: (a) Slab B1, (b) Slab B2, (c) Slab B3 and (d) Slab B4 


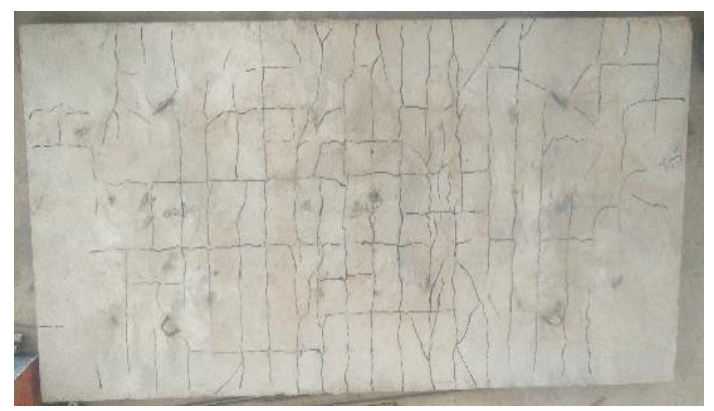

(a) Cracking pattern on the top surface

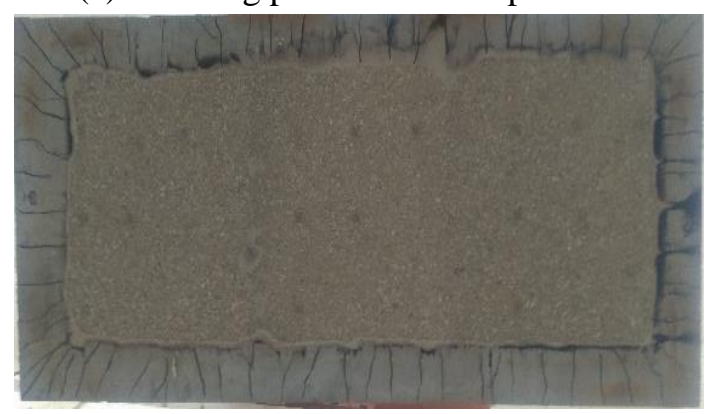

(c) Bottom surface

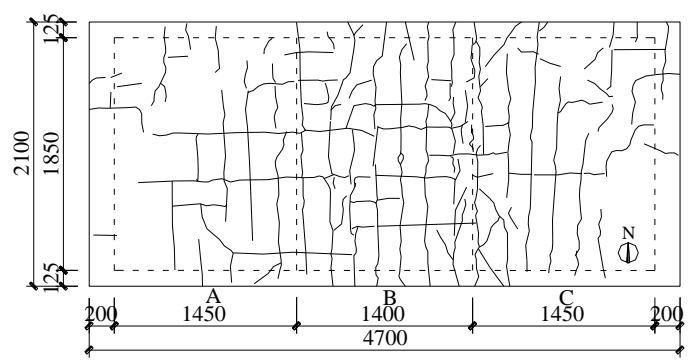

(b) Crack development during the test

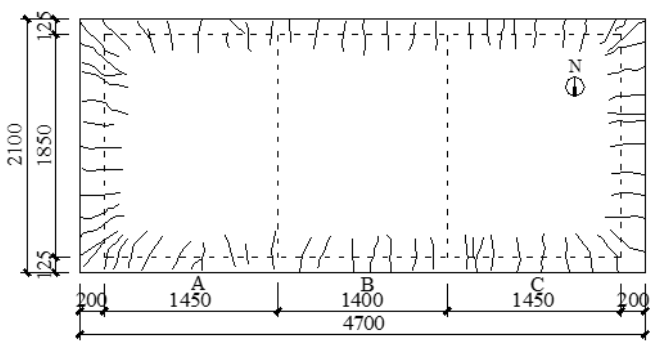

(d) Cracking pattern on the bottom surface

Fig. 24 Failure modes of Slab B1: (a) cracking pattern on the top surface, (b) crack development, (c) bottom surface and (d) cracking pattern on the bottom surface 


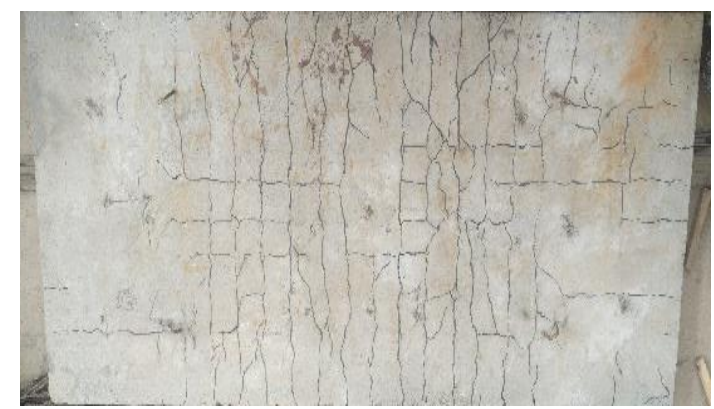

(a) Cracking pattern on the top surface

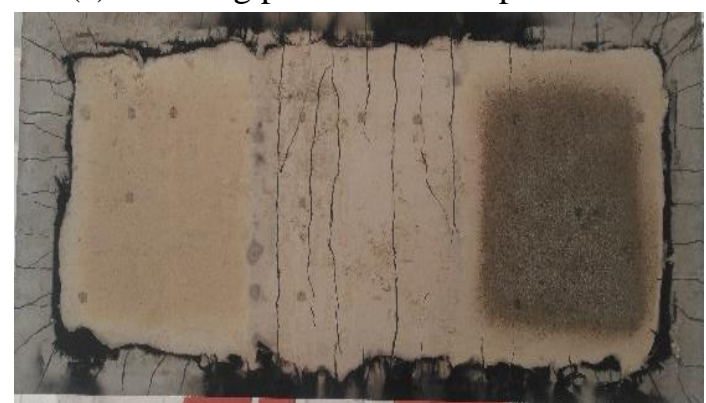

(c) Bottom surface

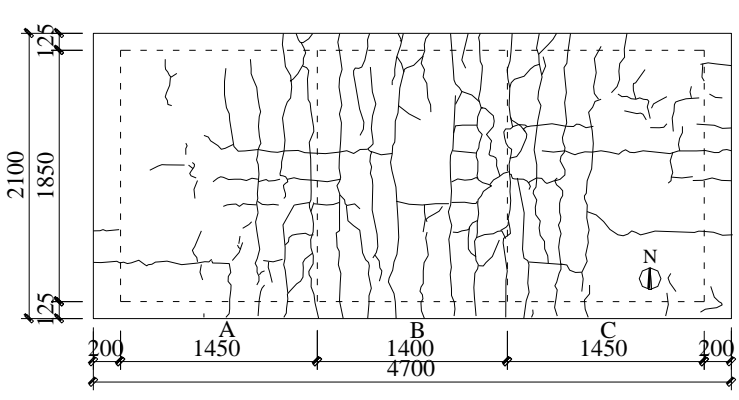

(b) Crack development during the test

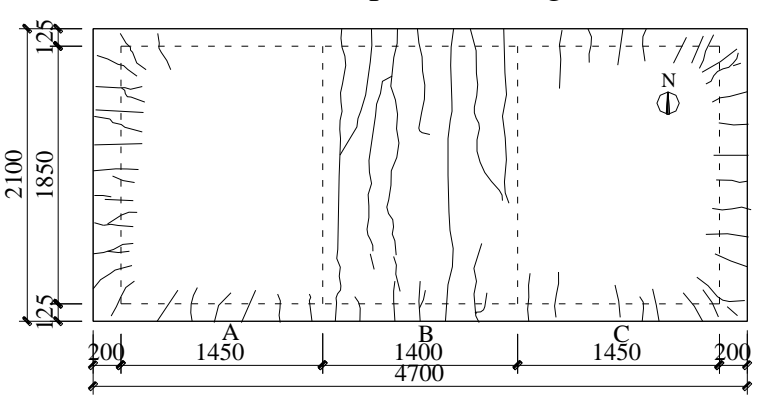

(d) Cracking pattern on the bottom surface

Fig. 25 Failure modes of Slab B2: (a) cracking pattern on the top surface, (b) crack development, (c) bottom surface and (d) cracking pattern on the bottom surface 


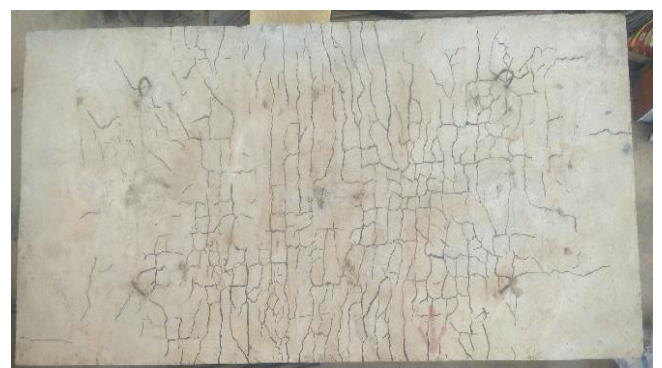

(a) Cracking pattern on the top surface

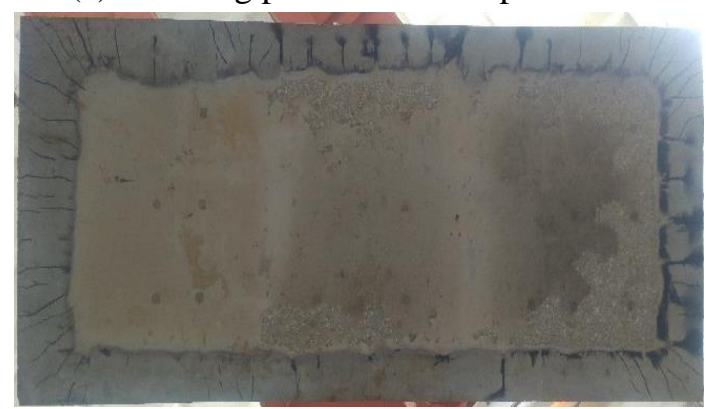

(c) Bottom surface

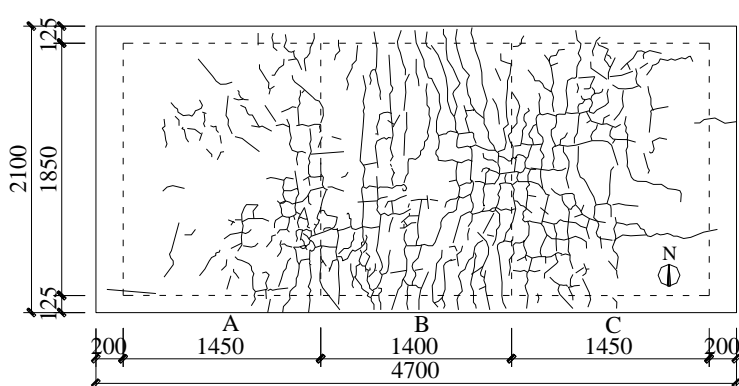

(b) Crack development during the test

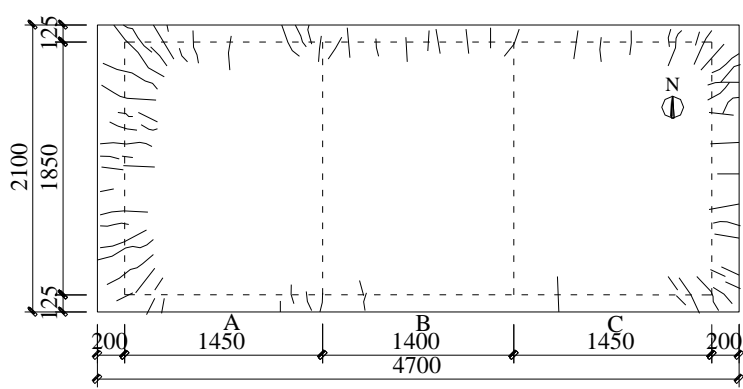

(d) Cracking pattern on the bottom surface

Fig. 26 Failure modes of Slab B3: (a) cracking pattern on the top surface, (b) crack development, (c) bottom surface and (d) cracking pattern on the bottom surface 


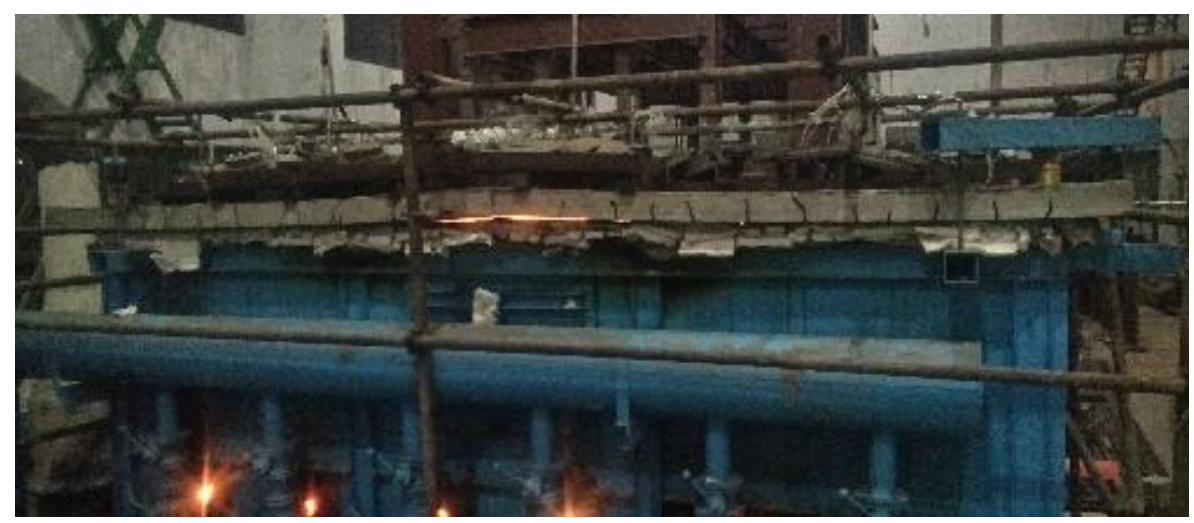

(a) Upward deflection behaviour of Compartment B

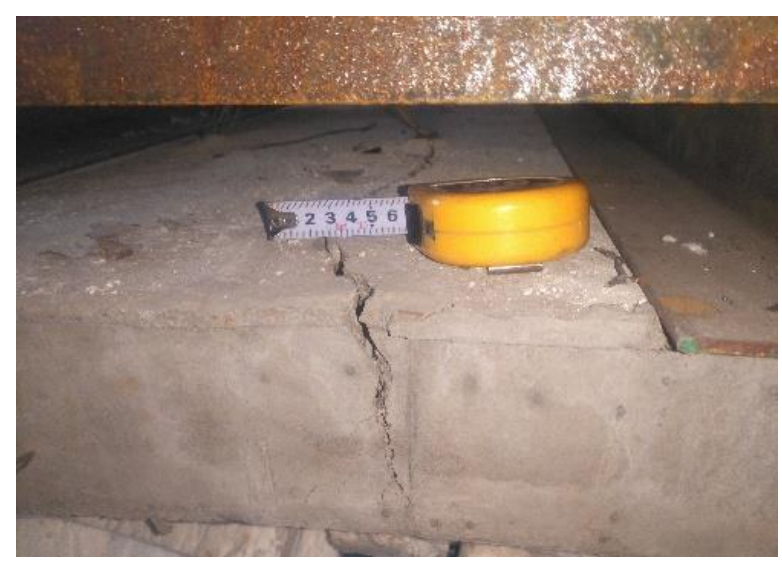

(b) Main crack

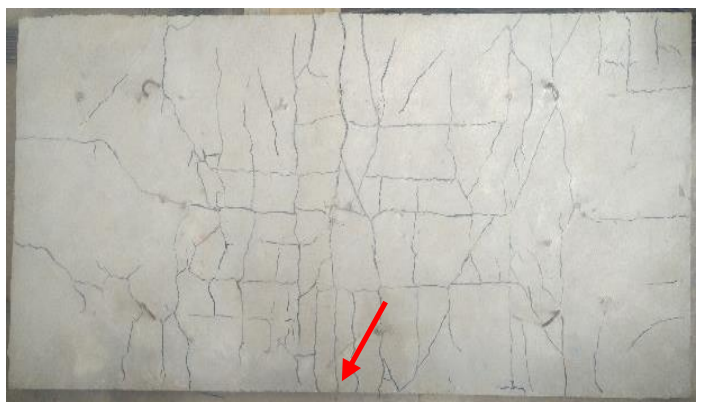

(c) Cracking pattern on the top surface

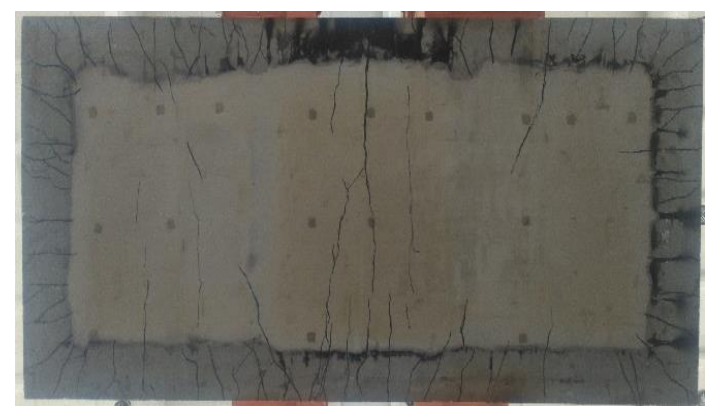

(e) Bottom surface

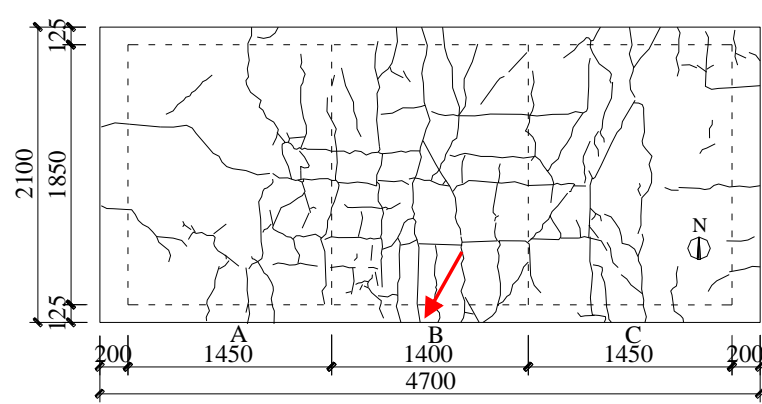

(d) Crack development during the test

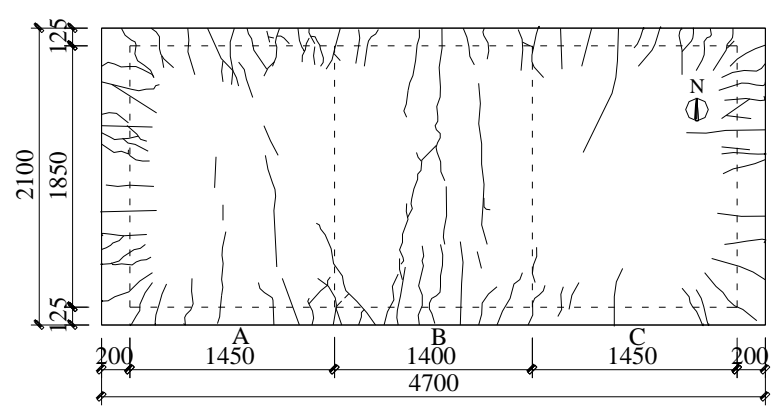

(f) Cracking pattern on the bottom surface

Fig. 27 Failure modes of Slab B4: (a) upward deflection behaviour of Compartment B, (b) main crack, (c) cracking pattern on the top surface, (d) crack development, (e) bottom surface and (f) cracking pattern on the bottom surface 